Article

\title{
Implementation of a TeamWork-HBIM for the Management and Sustainability of Architectural Heritage
}

\author{
Juan E. Nieto-Julián ${ }^{1}\left(\mathbb{D}\right.$, Lenin Lara ${ }^{2,3} \mathbb{D}$ and Juan Moyano ${ }^{1, *(\mathbb{D})}$ \\ 1 Department of Graphical Expression and Building Engineering, University of Seville, 41012 Seville, Spain; \\ jenieto@us.es \\ 2 School for the City, Landscape and Architecture, CipArq, International University of Ecuador, Simón Bolívar \\ Av. and Jorge Fernández Av., 170411 Quito, Ecuador; mlara@uide.edu.ec or \\ lenin.lara.calderon@alumnos.upm.es \\ 3 DTCA-Department of Construction and Architectural Technology, Polytechnic University of Madrid, Juan \\ de Herrera Av., 28040 Madrid, Spain \\ * Correspondence: jmoyano@us.es
}

check for

updates

Citation: Nieto-Julián, J.E.; Lara, L.; Moyano, J. Implementation of a TeamWork-HBIM for the

Management and Sustainability of Architectural Heritage. Sustainability 2021, 13, 2161. https://doi.org/ $10.3390 /$ su13042161

Received: 8 December 2020

Accepted: 1 February 2021

Published: 18 February 2021

Publisher's Note: MDPI stays neutral with regard to jurisdictional claims in published maps and institutional affiliations.

Copyright: (c) 2021 by the authors. Licensee MDPI, Basel, Switzerland. This article is an open access article distributed under the terms and conditions of the Creative Commons Attribution (CC BY) license (https:// creativecommons.org/licenses/by/ $4.0 /)$.

\begin{abstract}
The benefits of Building Information Modelling (BIM) accrue from the needs of the interoperability of applied technologies. This scope is strongly related to heritage buildings. Protection plans encompassing phases of heritage conservation, interpretation, intervention and dissemination could lead to a sustainable model through a TeamWork-HBIM project. This work develops a step by step semantically enriched 3D model, from accurate data acquisition to the creation of a container of artistic assets. TeamWork-HBIM acts as a database for movable assets, i.e., parametric objects (GDL) with graphical and semantic information, which are valid for recording, inventory and cataloguing processes. Thus, heritage properties were created and used to create recording and inventory sheets related to movable assets. Consequently, a parametric object was edited in the HBIM project, so a new category called "Heritage Furniture" was available. Data from the monitoring of the artistic asset were included in that category. In addition, the specialist technicians from the TeamWork-HBIM team catalogued a dataset related to artistic, historical and conservation properties. Another advantage of the system was the reliability of the structure of the HBIM project, which was based on the actual geometry of the building provided by the point clouds. The information was valid for both modelling works and specialists in virtual monitoring. Moreover, the reliability of metadata was collected in a common data environment (CDE), which was available for everyone. As a result, the TeamworkHBIM-CDE project meets the needs of private institutions, such as the Foundation of the Church of the Company of Jesus in Quito, related to the sustainability of the historic site. This sustainability is shown by the implementation of a methodology that strengthens the interdisciplinary information flow by including all disciplines of historical heritage.
\end{abstract}

Keywords: HBIM; sustainability; cataloguing; scanning laser; scan-to-BIM; intervention in the architectural heritage; TeamWork project; Quito; Church of the Company of Jesus

\section{Introduction}

Sustainability constitutes a main approach in any area of our society. Today, this aspect is being studied in works on heritage architecture. The benefits of the Building Information Modelling (BIM) digital platform accrue from the needs of the interoperability of applied technologies [1], and this scope is strongly related to heritage buildings. Moreover, sustainable restoration projects have been created and included in the heritage building information modelling (HBIM) paradigm. HBIM is a tool that manages both a great deal of information from graphic modelling and information provided by agents and operators related to restoration. There are also studies on sustainable qualification tools for heritage buildings that indicate the factors and indicators that allow sustainability to be analysed [2]. 
Few studies have confirmed that BIM tools can be included in the application of the sustainable restoration of heritage buildings [3], in which HBIM facilitates the usability and sustainability in the intervention process at different levels $(2 \mathrm{D}, 3 \mathrm{D}, 4 \mathrm{D}, 5 \mathrm{D}$ and $6 \mathrm{D})$ and work phases [4]. The modelling process of a heritage building faces both great challenges and complexities. Likewise, the set of activities includes the reverse engineering of the geometric analysis of buildings through the massive data capture using LIDAR technology [5]. Historians, architects, and archaeologists play key roles in historical heritage analysis as they provide both an accurate knowledge of buildings and interesting scientific data about the catalogued properties. On the other hand, the BIM platform has been developed by engineers and architects qualified to model heritage buildings. In this regard, the scientific literature has instigated the interest in the processes of a heritage project, thus improving the practical implementation and gathering better documentation [6]. Some processes are related to operativity, and others to management. If both efforts are united among the conservation technical teams, historians, archaeologists and the managers of the HBIM project, there will be an effective contribution in the sustainability standards. There is no system that assesses the sustainable performance of restoration projects [7], but this work could be the beginning of the development of a view on heritage sustainability.

\section{Literature Review}

Conservation and restoration operators of cultural heritage $(\mathrm{CH})$ could carry out an effective work by both reinforcing the dissemination and sharing specific information with accuracy techniques and innovative methodologies; today, those provided by geomatics and the Open BIM methodology are used.

Current protection plans of historic sites that encompass phases of preventive conservation programming, interpretation, intervention and dissemination of heritage could lead to a sustainable model by using the HBIM platform, thus improving resource management in 3D models, creating an interoperable environment with the intervention agents [8], and developing connective programmes between the BIM software and the virtual reality for dissemination purposes. Many studies on the management of the HBIM platform discuss these issues, including preventive maintenance [9], conservation management [10], and heritage dissemination. However, few studies have discussed the communication and information influx among operators to make the system sustainable. Most studies on semantic creation were discussed by [11] under the umbrella notion of the Conceptual Reference Model (CIDOC-CRM), and [12] used an ontology editor, TopBraid Composer, to represent and characterise the characteristics. The CIDOC-CRM [13] has become an ontological referential model that allows the information of $\mathrm{CH}$ to be formally and highly specifically represented [14].

The aforementioned reverse engineering process is intended to be used for the automatic or semiautomatic transformation of three-dimensional point clouds, focused on HBIM [15-18]. Most semiautomatic processes require complex software, in which many experts participate, because current BIM digital platforms cannot automatically work. Including a dense point cloud of a building in this digital platform is among the difficulties, together with the fact that, even for existing open platforms to manage cloud points for the automatic segmentation, such as the Point Cloud Library (PCL) [19], current BIM software cannot make a semantic segmentation of the morphology of the elements. Except in cases $[20,21]$ where the process is automatic. Reverse engineering in heritage buildings is therefore more and more complex. On the other hand, the BIM modelling process is designed following a constructive logic: it starts with the construction elements from the foundation phase and ends with the roof, installations and auxiliary elements. This process has nothing to do with reverse engineering as the massive data captured from LIDAR technology show both the skin of the building and the elements superficially joined to it. These data are recorded in files with great deal of information that cannot be used in BIM digital platforms. For this reason, new strategies related to the interoperability of accurate modelling systems should be developed [22], and especially those related to data management and new sustainable scenarios. This paper includes the implementation of a 
TeamWork-HBIM methodology that strengthens reciprocal information flows among all the participating areas of specialist technical teams and operators. The application example is the Conservation Plan of the Church of the Company of Jesus, which is the badge of the Latin American baroque erected by the Jesuit order between 1605 and 1765. This work is the beginning of the interventions programmed for an integrated and sustainable management project of the city's heritage.

Workflows in $\mathrm{CH}$ lack clarity in processes and information dissemination, and tools are rendered obsolete by heritage institutions [6]. Geometric data for the three-dimensional reconstruction should contain important information in management and physical information processes [23]. To join both processes, a new paradigm in the documentation of sites and monuments emerges, a digital platform based on BIM and applied to heritage. The works dealing with the methods and tools to manage information to diagnose and monitor buildings suggest a high semantic level of the original documents [24]. To solve semantic data management, Bruno et al. [24] proposed the use of both BIMcloud services and a BIM repository to reduce the size of deliverables.

Technical teams collaboratively work through database files that are interchangeable with the BIM digital platform. The main problem is metadata management, which is solved by software such as ArchiCAD ${ }^{\circledR}$ from Graphisoft through interoperability operations with exportable files (.xlsx) from the data scheme. Revit works similarly with the file export through schedules. These technical teams work collaboratively with Excel formats that are interchangeable with the BIM digital platform. This way of working with external operators has been used by both Moyano et al. [23] in stratigraphic units within archaeology, and Bienvenido-Huertas et al. [25] to implement a model to classify tiles in the Pavilion of Charles V through artificial intelligence. Pocobelli et al. [26] used, with the Revit platform, spreadsheets linked to smart masses. In addition, Bruno et al. [27] mentioned the simplification in database management through Access, SQL Server or Excel files. These researchers developed a methodology to guarantee nongeometric information and data management. The Architecture, Engineering and Construction (AEC) industry is involved in the sustainable management of buildings and infrastructures. For this purpose, the Industry Foundation Classes (IFCs) format emerged as a 3D model of standard and open data that reinforces the interoperability of the system. This functionality removes the gap between data collection and analysis, thus improving the productivity and providing greater flexibility to the BIM system. IFC models are essential in an HBIM project. IFC's main characteristics are defined with the EXPRESS language (ISO/TC 184/SC 4.1994) [28]: the headline section, types, entities, functions and rules. The headline section provides generic information about the scheme; types and entities are directly related to data definitions; functions and rules define the limitations imposed on definitions [28]. An IFC model is considered as a dynamic database in which a great deal of information (i.e., the material of the object, the physical relation with other models and the mechanical properties) could be included. Apart from geometry, the elements should also be allocated to both classes of objects and typological subdivisions [29]. The problem emerges when the operators do not know the usual roles of the AEC industry, as occurs in $\mathrm{CH}$ with very specific disciplines such as archaeology or the restoration of movable assets to meet the requirements of $\mathrm{CH}$. In this line [30], a more dynamic and open platform is implemented. The system is divided into open-code protocols; a 3D model in the FreeCAD software was exported in IFC to link the information appropriately to DBMS, thus allowing its management. Another way to mitigate this issue is by using applications such as dRofus [31], a tool of planning, data management and BIM collaboration, which allows the spaces and their requirements to be included in the BIM model. As a result, architects and engineers, and operators in general, can capture and organise the planning requirements of the client and use them to validate and propose alternatives in the design process.

In general, a research method to manage heritage buildings should be proposed because of the dispersion of information generated by a $\mathrm{CH}$ project [32]. BIM could remove gaps related to the lack of studies during the construction project and plays a crucial role 
in the Key Performance Indicators (KPIs) [33]. On the other hand, BIM supports new workflows related to sustainability indicators. The authors of [2] define five methodologies defined in the Sustainability of Heritage Buildings (SHBs)-i.e., simulation, visualisation, HBIM environment, the energy study and multicriterion decision-making; moreover, there is a scale differential for all these methodologies in the studies on sustainability. In this context, TeamWork develops a work divided into four sections. The first section indicates the research cycle of the methodology; the second section focuses on both the skills to acquire the actual geometry of the $\mathrm{CH}$ asset and the postprocessing of the cloud point to make it easily accessible in the collaborative environment of the project and to support the structure of the parametric HBIM model; the third section shows the TeamWork-HBIM system and its linking with a common data environment (CDE) as a collaborative and interoperable tool; finally, the methodology is applied as a specific case study to the inventory and cataloguing of the artistic assets included in the Church of the Company of Jesus.

\section{Research Methodology}

Certainly, this is a way to structure the documentation in an HBIM project, in which the operativity of the system allows specialists and TeamWork to collect data in the maintenance and conservation phases. These program files show specific data, but their use leaves behind valuable information, such as photographs and graphic documents that also belong to the history of the building and $\mathrm{CH}$. This work develops a methodology based on an information interchange in an active project included in a BIM digital platform. The procedures used, in which operators work in real time to implement the HBIM project, turned it into a sustainable project. The massive data capture (MDC) of the point cloud was obtained with a Terrestrial Scanning Laser (TLS) to contribute to the accuracy and similarity of the morphological characteristics of the object. For this purpose, a parallel system from the Leica JetStream software was used because actual measures could be explored and acquired. The project to interchange information among coworkers emerged by applying TeamWork, a functionality also included in the same platform. Based on this operativity, movable assets catalogued by the National Heritage Institute of Equator were managed.

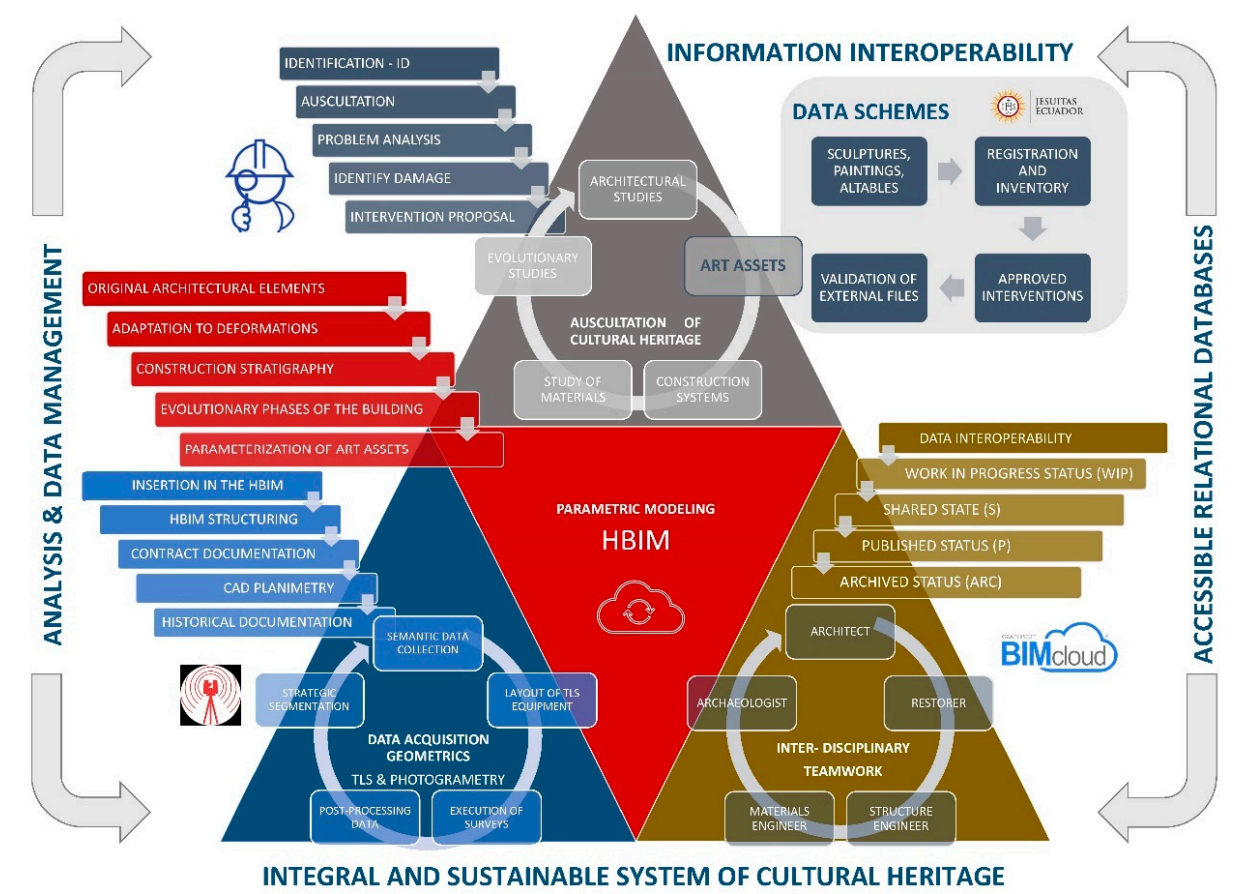

Figure 1. Methodological process applied to cultural heritage $(\mathrm{CH})$ sustainability. 
Any external collaborator agent can easily access data thanks to the use of a common data environment (CDE). The process in a $\mathrm{CH}$ intervention is circular and fed back (Figure 1). This means that it acts as a method to control the procedures, in which the results obtained in an initial stage are again included in the system to be optimised.

Under this flow diagram, the goal of this work is the generation of a sustainable platform which includes the database in a digital information model. This is the first research stage integrated by the collaborative work TeamWork using a CDE structure. The project management is focused on research, preservation, restoration, and heritage dissemination; in addition, it is implemented in a specific case of movable or artistic assets.

\section{Case Study, Equipment and Postprocessing}

The Church of the Company of Jesus (Figure 2b) is one of the emblematic historical buildings in Quito. It is the most representative baroque temple of the colonial America period. Its construction began at the beginning of the 17th century, lasting 160 years. The church is composed by a single nave, communicating chapels and a transept corresponding to the northern and southern chapels, presbytery and vestry. The dimensions and artistic characteristics of the temple have been defined by [34]. One of the elements with the highest artistic value is the pulpit joined to one of the pillars dating from 1675 [35]: it is carved in cedar wood, with fretwork and gilding in gold leaf, has the form of a chalice and includes more than 250 images of religious figures of the Jesuit order [36,37].

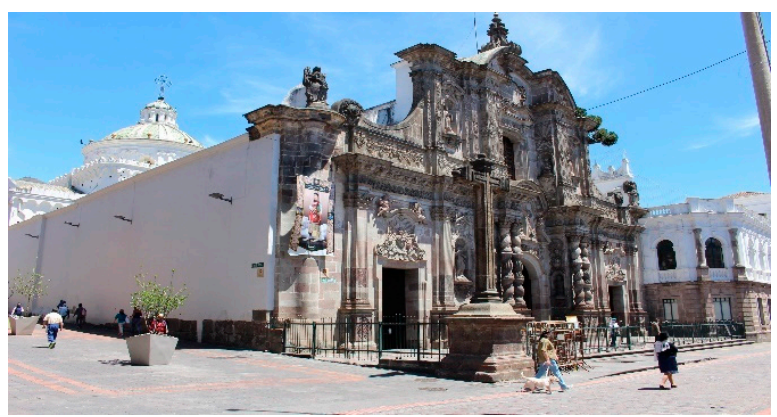

(a)

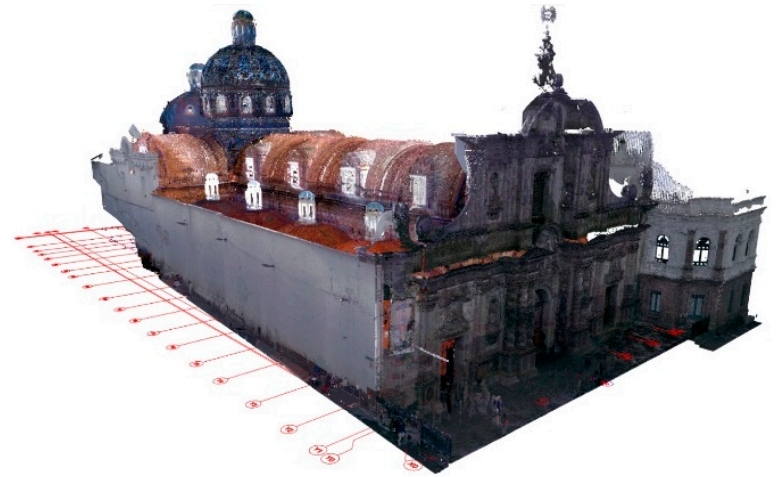

(b)

Figure 2. (a) Photograph of the exterior of the Church of the Company of Jesus; (b) view of the point cloud included in the HBIM project using the ArchiCAD software.

\subsection{Data Acquisition Procedure}

The TLS scanning process was carried out through several campaigns. Captures were taking in both the exterior and the interior to acquire the complete geometry of the Church of the Company of Jesus; a coupling and alignment of the range cloud were used by effective and accurate procedures, as the recording report of Cyclone REGISTER 360 shows. The TLS technique compiles space data precisely $[38,39]$. Surveys were conducted at five levels (Table 1) to cover most of the surface of the church. The five levels were as follows: in a platform, in the stem of the arches, in the chorus stand, in the upper balcony next to the chorus and in the corridor of the lantern under the dome. 
Table 1. Total number of the valid scans processed at various levels.

\begin{tabular}{ccccccc}
\hline Scans & $\begin{array}{c}\text { Level 1 } \\
(+\mathbf{1 . 0 0 )}\end{array}$ & $\begin{array}{c}\text { Level 2 } \\
(+\mathbf{+ 5 . 7 0 )}\end{array}$ & $\begin{array}{c}\text { Level 3 } \\
(+\mathbf{+ 8 . 7 0 )}\end{array}$ & $\begin{array}{c}\text { Level 4 } \\
\mathbf{( + 9 . 6 0 )}\end{array}$ & $\begin{array}{c}\text { Level 5 } \\
(+\mathbf{+ 1 9 . 9 0 )}\end{array}$ & Total Sum \\
\hline Valid & 71 & 13 & 19 & 9 & 3 & 115 \\
Null & 2 & 0 & 0 & 0 & 0 & 2 \\
Total scans processed & 69 & 13 & 19 & 9 & 3 & 113 \\
\hline
\end{tabular}

A Leica BLK360 laser scanner was used with a range of $120 \mathrm{~m}$ to capture the geometry. The performance of this equipment was studied by [40], which confirmed an accuracy of the scanner from $6 \mathrm{~mm}$ to $10 \mathrm{~m}$ to record control points. Scans were made with a high resolution HDR 15 Mpixel 3-camera system, thus obtaining an accurate laser range. Data captured by the laser scanner were previously treated by reconsidering the position of the equipment, so that the $360^{\circ}$ scan could record the spaces of the two lateral naves, the central nave, chapel and vestry. The distribution was fair, so the distances did not exceed $5 \mathrm{~m}$. The time of each scan, with a $360^{\circ}$ scan with a high quality HDR image, was up to $5 \mathrm{~min} 30 \mathrm{~s}$. The details in both vaults and high areas were covered by strategic positions of the equipment, which was placed in the chorus stand, behind the perimeter rail of the central nave and in the upper tambour under the dome. Height scanning of the façade and vault intrados was possible by using high platforms of aluminium mobile scaffolds, so an Unmanned Aerial Vehicle (UAV) system was not required. After records were obtained, the postprocessing was carried out with the Leica Register 360 software, generating two global point clouds: 37.037 .014 (level 1) and $48.489 .690 \mathrm{~kb}$ (levels 2-3-4), in .e57 format.

Table 2 shows the result for each scanning set. After coupling the placements, the software generated an overlapping report and the quality matrix of the links. The trust or strength level was greater than $85 \%$ in the three sets.

Table 2. Result of the reports with error expression in the placement set.

\begin{tabular}{cccr}
\hline TLS Placements & Level 1 and Façades & Upper Levels: 2-3-4-5 & Façades \\
\hline Number: & 75 placements & 38 placements & 16 placements \\
\hline Number of connections: & 214 & 83 & 32 \\
\hline Strength: & $88 \%$ & $85 \%$ & $84 \%$ \\
\hline Overlapping: & $57 \%$ & $51 \%$ & $65 \%$ \\
\hline Set error: & $0.007 \mathrm{~m}$ & $0.007 \mathrm{~m}$ & $0.006 \mathrm{~m}$ \\
\hline Cloud to cloud error: & $0.007 \mathrm{~m}$ & $0.007 \mathrm{~m}$ & $0.006 \mathrm{~m}$ \\
\hline
\end{tabular}

\subsection{Postprocessing}

Two main challenges were faced in the postprocessing of the point cloud. The first challenge was working with the dimensions of the file size; because of their extension, the files could not be used in BIM digital platforms (Revit ${ }^{\circledR}$ Autodesk or ArchiCAD ${ }^{\circledR}$ Graphisoft). To reduce the file size, filtering and a segmentation were carried out. Nondesirable noise and objects were removed in the filtering. On the other hand, point cloud data were processed and organised into significant subsets in the segmentation [41]. The second challenge was keeping the information of the point cloud within the same coordinate system, in which each segmentation had a value $\left(\mathrm{x}_{\mathrm{i}}, \mathrm{y}_{\mathrm{i}}, \mathrm{z}_{\mathrm{i}}\right)$ related to the object, so the segmented portions were well joined in their set when they were included. This segmentation step was carried out through deliberate structures and forms that were later modelled and catalogued within the TeamWork project. In the next phase, the point cloud portions processed with the Cyclone Register 360 software were exported in an interchange format (.ptx) to maintain the filtering and the segmentation applied. 


\subsection{Exploration of the Point Cloud}

To visualise the point cloud to be recorded and verified after postprocessing with the Cyclone Register 360, Leica JetStream software [42] was used as its design allows the range cloud to be visualised (Figure 3). This is a viewer independent of the BIM digital platform that shows the original files created (.jsv and .lgs) and postprocessed by Cyclone Register 360. An instantaneous load of all points is provided and surfing through the cloud of the various records is possible, thus creating animations.

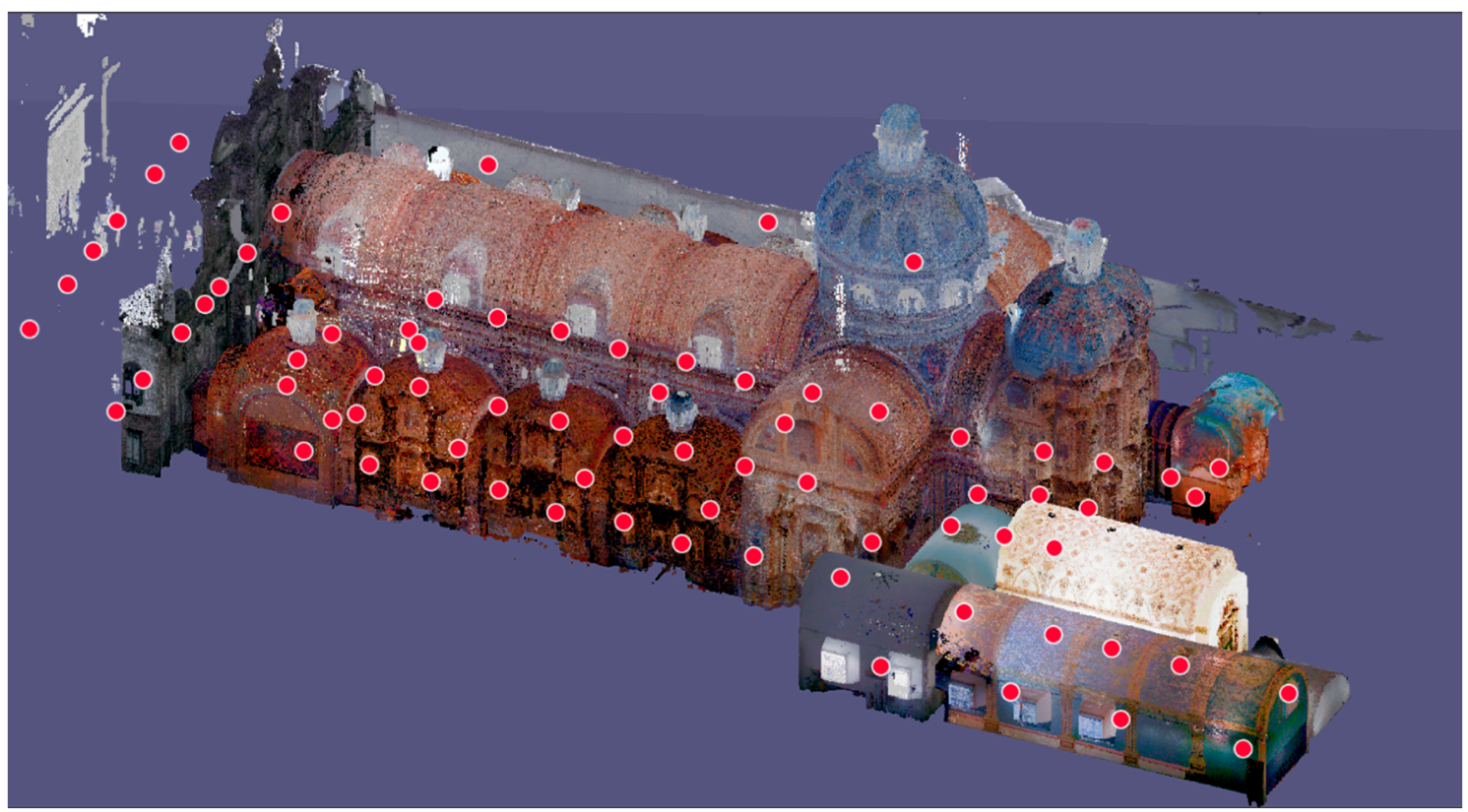

Figure 3. L1 point cloud processed with Cyclone Register 360 and visualised with JetStream Viewer.

\section{TeamWork-HBIM Project}

EN-ISO 19650 is a set of international standards defining the framework, principles and requirements to acquire, use and manage information in projects and assets throughout the building life cycle. According to these standards, BIM is the use of a shared digital representation of an asset built to ease design, construction and operation processes and to provide a reliable basis for the decision-making. On the other hand, the EN-ISO 19650-3 standard defines the processes to use and manage information during the operation or maintenance phase. This standard was developed by the International Standard Organization ISO/WD 19650-2: Organization of information about construction works [43]. In sectors such as the AEC industry, the transmission of information coordinated among actors is crucial, thus breaking new ground in improving the quality of the value chain. Implementing the interactive communication of different software is also essential because of the availability of digital means. The BIM methodology implicitly includes the concept of interoperating among users, and even clients themselves. As for ArchiCAD ${ }^{\circledR}$, Graphisoft included the concept TeamWork in version 5.1, presented in 1997. This collaboration method allows the members of the team to work on separate parts of the same project and to merge the work into a master file [44]. To meet the new AEC industry's needs, TeamWork projects are today managed by BIMcloud Graphisoft to guarantee teamwork in a reliable and continuous way [45] and to ease the use of large files. The profitability of the teledetection work is also increased before starting the Level of Development (LOD) of the 3D model. Moreover, the methodology would allow units of research studies on intervention, conservation and maintenance to be included. Delta-server technology is used to send and receive operations more quickly. There is a common data environment (CDE) to work with, thus making modelling in parallel possible; this is helpful to hasten 
the development of the project. As a result, a robust architecture of the system is created, where BIMcloud ensures the integrity of the BIM project.

The TeamWork methodology has been used as a learning strategy implemented by the engineering schools, which are based on Team-Based Learning (TBL) [46], so students could follow a collaborative process to improve the participation of all members. This participation is based on experience, cohesion skills and teamwork [47]. If the BIM technology, including its skills, is implemented in $\mathrm{CH}$ with a more active approach in which the collaborative process plays a key role, a new paradigm will be developed in the historical construction sector and its conservation.

\section{1. $C D E$}

The information and data interchange of an active project, based on the BIM methodology, should be managed in a structured and safe way. For this purpose, a CDE should be used to meet, manage and divide each container of information through an established procedure (EN-ISO 19650-1). Studies are increasingly focused on presenting the benefits of implementing a CDE in construction projects, although $\mathrm{CH}$ sustainability has not been applied yet [48-51]. The client should provide an open common digital space (within the same work platform) to which all the members of the team could access to share the information of the collaborative project. In this regard, the Foundation of the Church of the Company of Jesus delegated the CDE to the researchers from both the University of Seville and the UIDE. A server was available to store all the information of the TeamWork-HBIM project, based on the ArchiCAD ${ }^{\circledR}$ platform, to be managed by the whole technical team to review or modify according to their role.

For the correct operativity of the CDE in the Church of the Company of Jesus, the agents with management roles of the model who were responsible for centralising the information were defined. This was important to guarantee a standardisation and a homogeneous data structure because specific information from several disciplines (architectural, structural, historical and artistic disciplines) would be available. According to the BIM execution plan (BEP) established for the HBIM project, the access to information was limited to coworkers with permissions and user control. A BIM manager was appointed as responsible for both establishing the structure of the project, included in the BEP, and ensuring its maintenance and integrity, especially of the BIM model by backing up regularly. In the management procedure of the $\mathrm{CDE}$, the information was structured in various states: Work-in-progress (WIP) state, applied to the information that is being developed by the teamwork; Shared (S) state, applied to the information that can be consulted by the appropriate parties; Published $(\mathrm{P})$ state, applied to the information authorised to be used; Archived (ARC) state, applied to the information shared and published, and which was therefore recorded.

In the interoperability phases with the agents specialised in restoration, the schemes of data exported from HBIM were also recorded in the same CDE. Thus, the same coworker, by accessing to the CDE, visualised and explored the 3D point cloud with the Leica JetStream Viewer as a support for the auscultation. The .xlsx data files, with the items already completed, were again included in the HBIM project in a flexible workflow, thus being automatically recorded.

The TeamWork + HBIM + CDE system was supported by the OpenBIM methodology, thus facilitating the interoperability among the agents involved. IFC open standard files were used, so the HBIM project was an asset that could be easily accessed, as well as sustainable. In addition, the internal work of structuring, modelling and coordination was guaranteed by the information flow through BIMCloud. Data structured in the Relational Database Management System (RDBMS) were linked according to the classification and properties provided by the BIM model. The system uses the SQL Server and is supported by the Transact-SQL language, an implementation of Microsoft of the ANSI standard. All the elements from the 3D model have been mapped with IFC properties or attributes in ArchiCAD before their export. The relationship between the HBIM Project and the DataBase is guaranteed by the specific Pset of each element within a well-structured IFC format. 
The IFC data model is available in the server that supports the DataBase, and all team members could access it. In this regard, the system allows various platforms to be included, so the BIM model data could be synchronised with other solutions of data management, processing and analysis.

The flow diagram (Figure 4) is described as follows: the 3D model of the TeamWork HBIM Project was interoperable by all the operators with role permission. The workflow with the external technical team was carried out through the retroactive data flow in Excel tables (.xlsx), thus allowing the validated information to be automatically introduced. The RDBMS was linked to an IFC transfer model that contained the information of the asset and where the IFC elements were well-defined (ID) and classified (IfcPropertySet) to be recorded in the DataBase. A web interface, mainly for consultants, allowed the DataBase to be accessed and managed. The 3D model could be consulted in two ways: with the viewer BIMx to explore the hyper-model completely (the .bimx file), with easy camera paths, and to review all the views, tables and planes (considering the corresponding limitations according to the permissions provided). Although BIMx was used in the web as an external consultation, it was mainly a Graphic Review Interface (GUI) of the specialist technician to maintain and conserve the asset and was used with mobile devices. The other method of consultation was the $360^{\circ}$ exploration of the full cloud point by using Leica JetStream Viewer. The consultant could access both HDR views and the actual measurements in the points captured by the scanner.

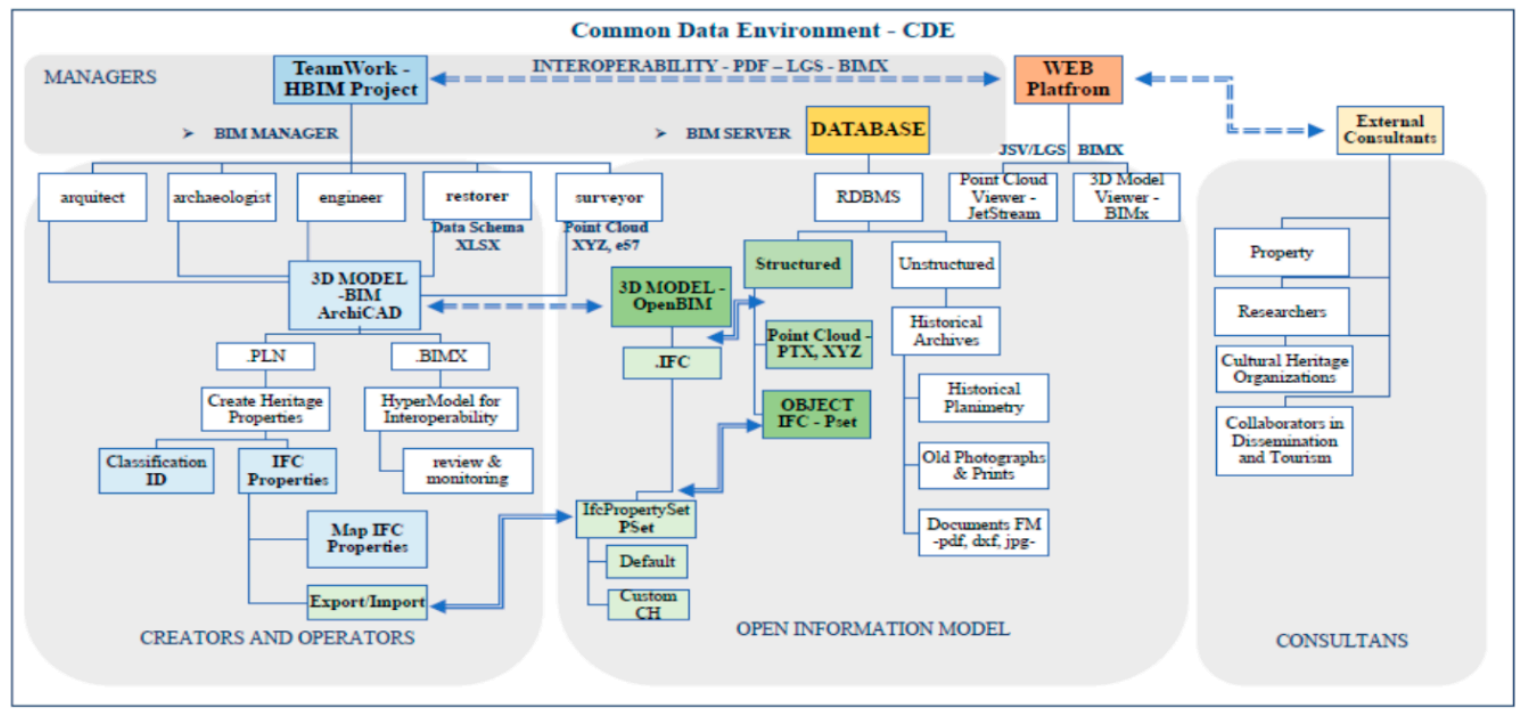

Figure 4. Graphic of the workflow of the TeamWork-HBIM-common data environment (CDE).

The proposed system aims to manage many data in relation to the conservation of a historical asset, although this document includes the workflow for an effective cataloguing of the paintings included in the building. The TeamWork-HBIM + CDE system guarantees the interoperability of data with the specialists in conservation and restoration, where the information flow is supported by the recording and inventory sheets expressly created for the HBIM project.

\subsection{Organisation or the Teamwork}

The interconnection of the TeamWork active methodology began by registering technical teams, engineers, architects and constructors in a Virtual Private Network (VPN). The information basis of the working field was made through a technical information system of the Equatorial $\mathrm{CH}$. The characteristics of the movable asset and immovable assets, such as altarpieces, sculptures, paintings and silverware objects, were recorded in this information system. For the initial information interchange, software that allow operators to be connected were proved. TeamWork is an interoperability system of BIM operators. Each BIM 
operator worked through a working role (e.g., architect-manager, modelling technician, or installation technician), and they accessed the editable parts with permission. The operation permission was given by the main manager who was responsible for structuring the HBIM project, so the functions of the operation were limited by this person. On the other hand, the dataset obtained by the remote sensing techniques was managed with appropriate software interoperating with TeamWork. For this purpose, after processing the range cloud with Cyclone Register 360, the Leica JetStream software was used as a tool to visualise the scanned model. Equally to FARO Cloudshare, Leica JetStream Viewer facilitated the interchange of data processed with Cyclone LGS, so external agents could explore the point clouds without requiring a use licence [52]. This viewer, with no antecedents, could be installed by each technical team to visualise and surf original data stored in an equipment in real time. The .jsv or .lgs files could be shared from a JetStream Enterprise server with an O-licence from Cyclone or Cyclone REGISTER $360+$ PUBLISHER.

\subsection{Sectorisation of the Point Cloud}

Many works dealing with the step from point cloud to BIM are related to segmentation. The semantic segmentation is a process that classifies the elements of the data of the range cloud according to the recognition of the architectural elements [20]. The connection between the point cloud and the BIM digital platform creates an appropriate workflow for the accuracy of the 3D reconstruction. This is a working area developed in the scientific scope that considers the recognition of primitive geometries for the step to BIM. As forms are complex, implementation methodologies are required to create parametric objects [23], but the segmentation step implies processes of techniques based on classification algorithms [53-56]. To avoid complex processes of semantic segmentation, this work was based on manual classification processes carried out by the same operator with Cyclone Register 360. The interchange from the point cloud to BIM was based on both segmenting the range cloud in an .xyz format and turning it into a parametric object such as a Library Container File (LCF) with the BIM digital platform. This segmentation was required for files exceeding 280 million points because the BIM digital platform could not process it. The sectorisation of the point cloud was established by scanned rooms in the church, instead of by levels (Figure 5). The rooms of the church (i.e., naves and vestry) were considered.

From this sectorisation, a subsectorisation of the point cloud was carried out to structure the identification of movable and immovable assets according to their categories. For this purpose, the set of assets including altarpieces, caring, silverware objects, sculptures and paintings was analysed. This sectorisation was aimed to obtain flexibility and sustainability of the system of the HBIM project (Figure 6).

\subsection{Structuring the HBIM Project with a Network System}

In the following experimentation phase, the point cloud sectors included in the HBIM project were structured in levels to proceed to the modelling. In practice, a BIM model is generated from the normal construction process-i.e., from the foundation to the roof through the various masonry and installation phases [57]. The levels of the project were readjusted with the Point Cloud Complete, although those obtained by the CAD planimetry (.dwg) were maintained; plans, elevations and sections were imported into worksheets to use them as references. One of the advantages of the ArchiCAD platform is using point cloud views, thus establishing an appropriate depth range for its correct interpretation and observation. In addition, this procedure compares the views with CAD projections, determines the adjustment among the previous planimetry and verifies the metric data in the HBIM project. So, plan views were generated with the same cutting level and identical sections to that of CAD to fulfil the criteria used in previous drawing-ups and to compare them. The applied process detected significant discrepancies with the actual geometry (Figure 7). Another system that promotes the sustainability of the Teamwork-HBIM project is the network system, which provides a network of axis and its linking to the project. 
One of its advantages is that it is used as both auxiliary lines and a reference of Cartesian coordinates; in addition, it automatises the insertion of many architectural elements, thus saving time and flexibility in the system (Figure 8).

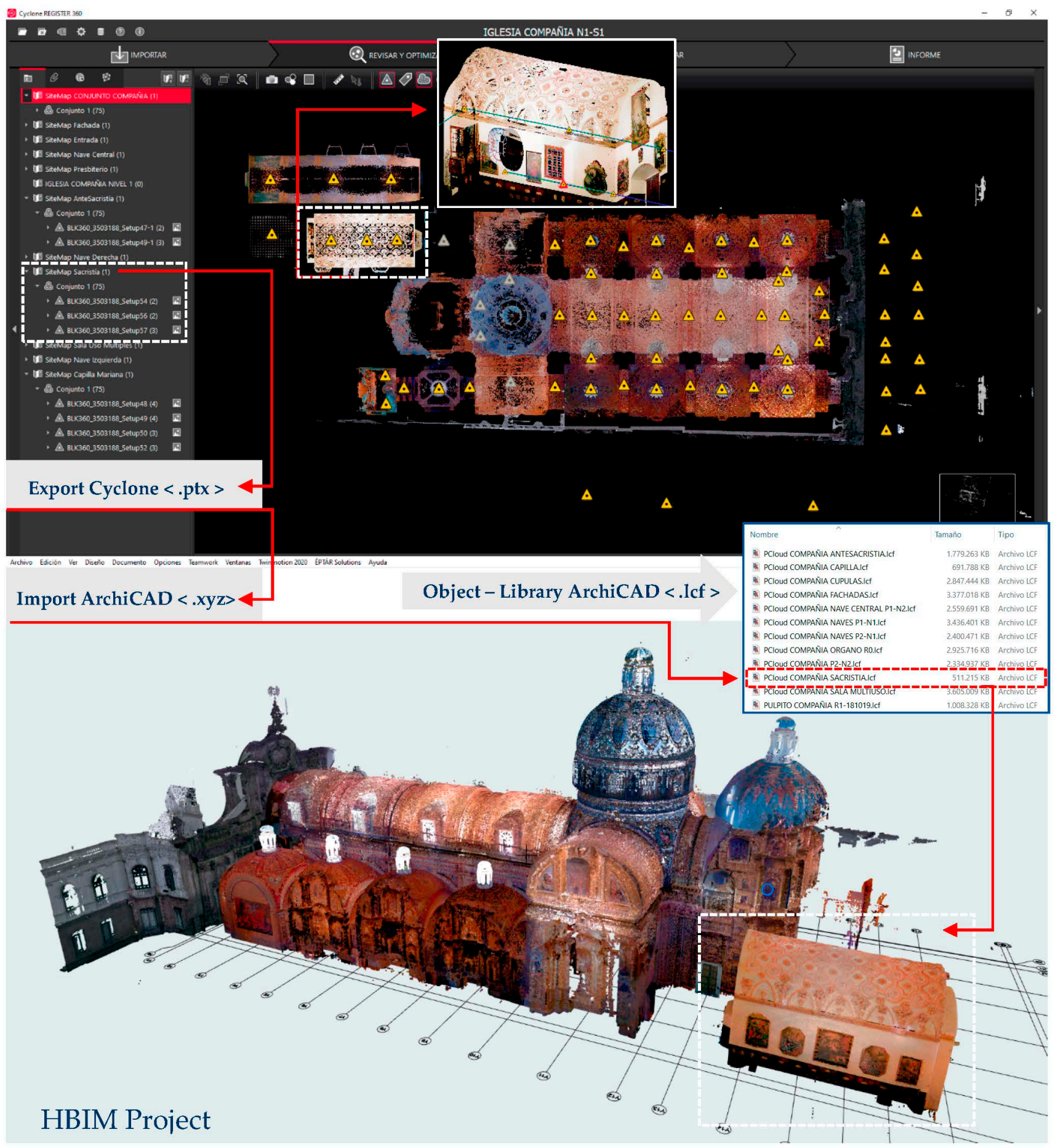

Figure 5. Sectorisation of the range cloud by rooms of the church. 


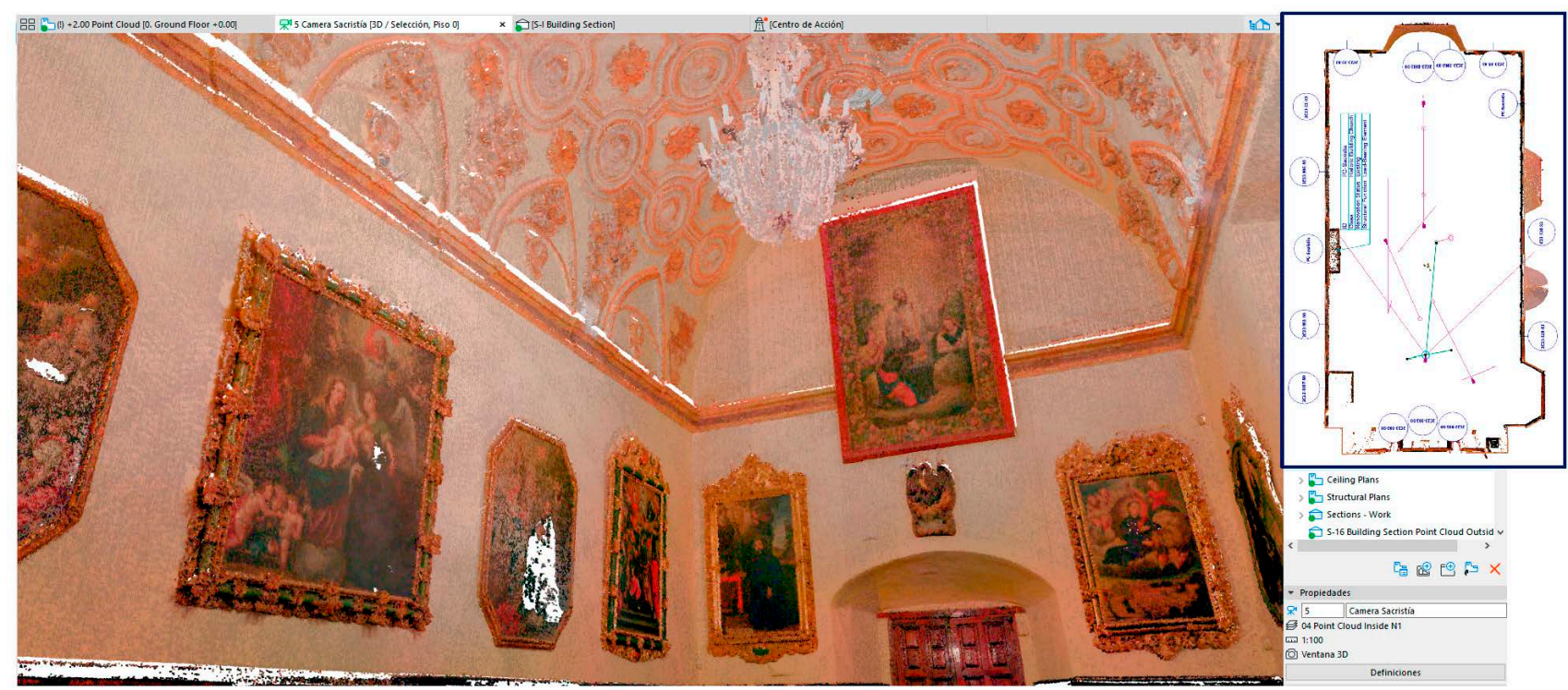

Figure 6. Point cloud of the vestry included in the HBIM project. The vestry is viewed from a 5 camera of the ArchiCAD platform.

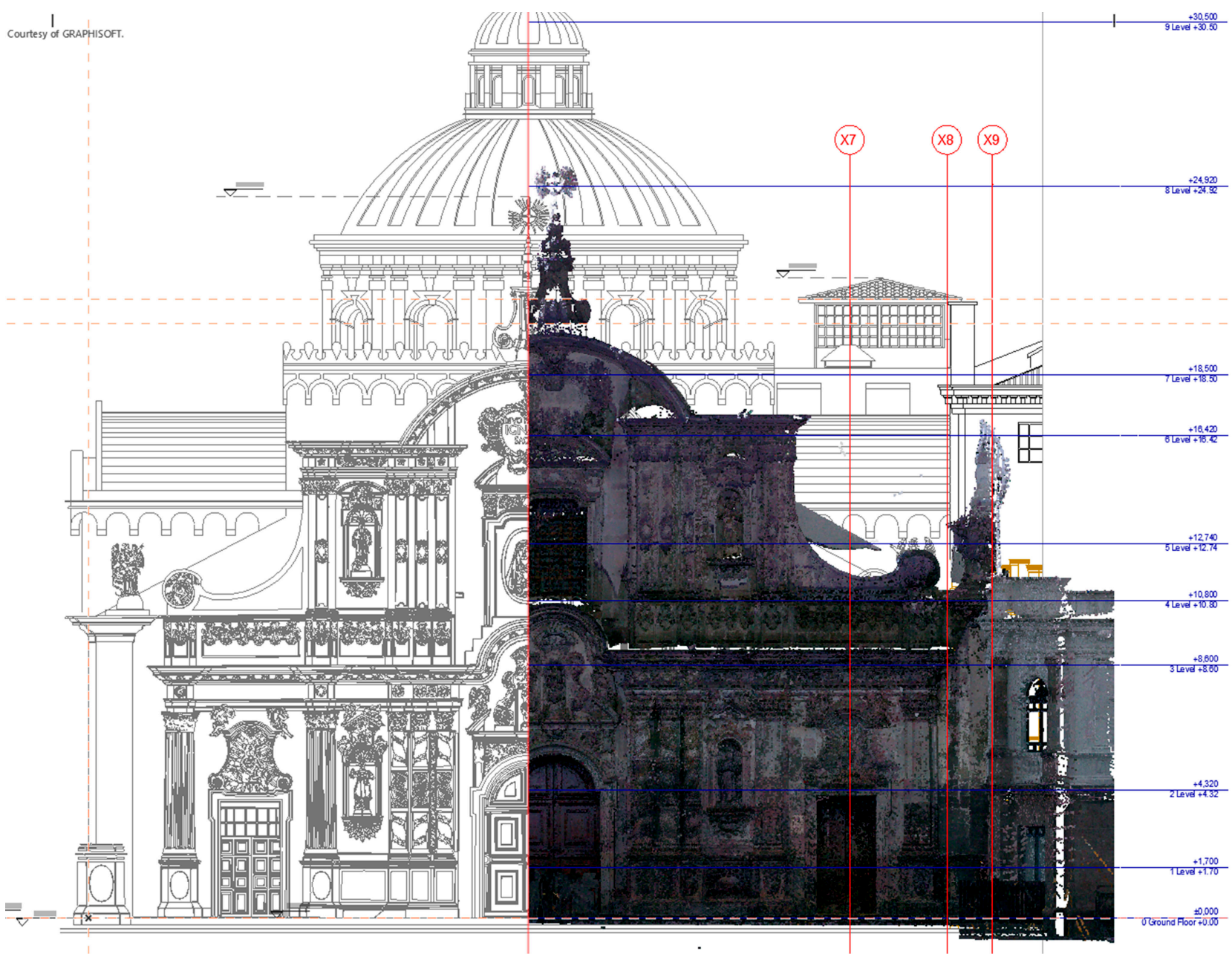

Figure 7. Comparison of the elevation of the façade, which was included as Template of CAD in HBIM, with the point cloud. A major deviation of $832 \mathrm{~mm}$ can be seen. ArchiCAD 24. 


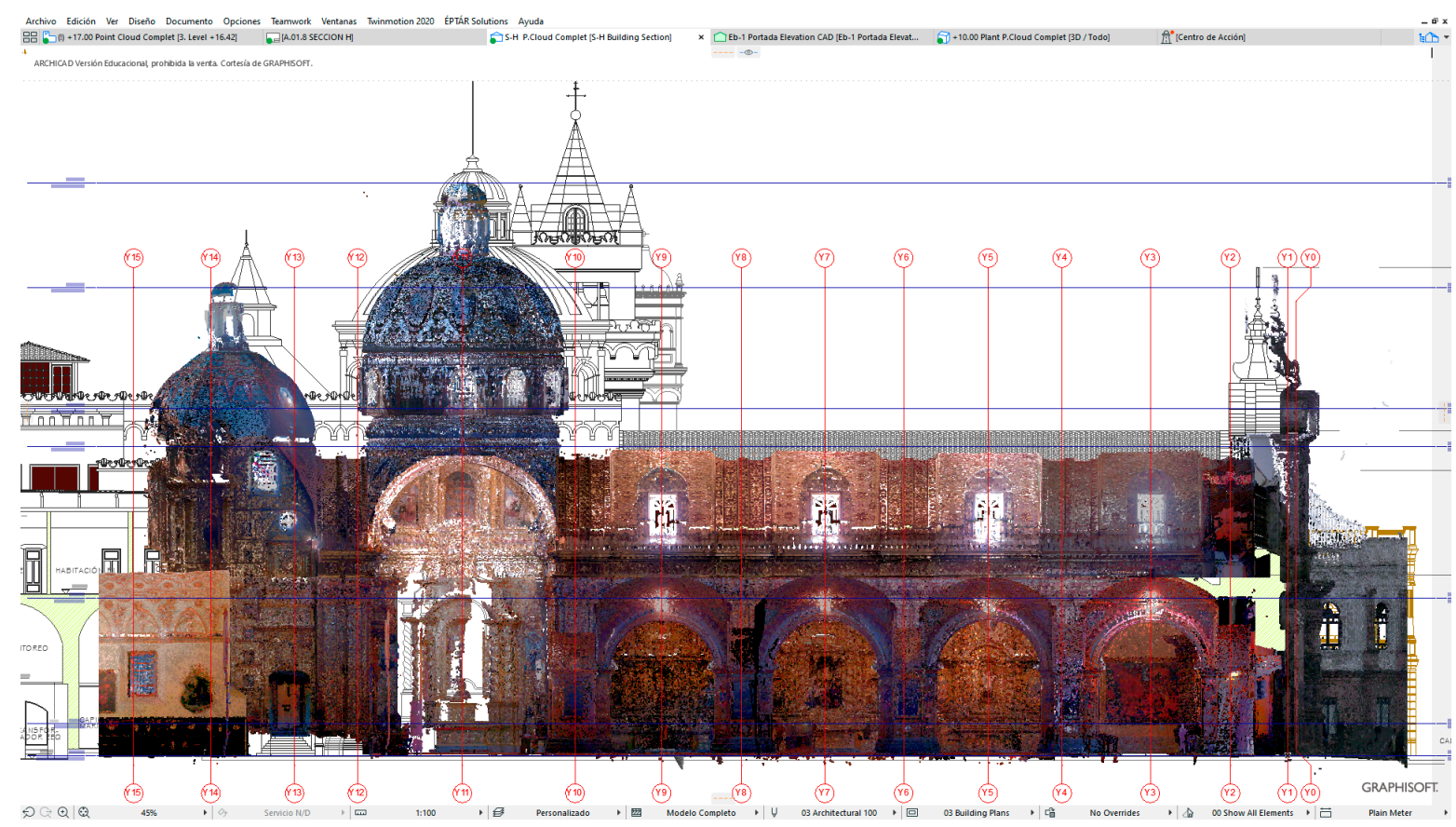

Figure 8. H-Section of the Point Cloud Complet included in the HBIM project and compared with the H-cutting of the CAD file; the top table shows the perspective of the point cloud with ArchiCAD.

\subsection{From the Database of the Immovable Assets to the Cataloguing in the HBIM Project}

ICTs and the Internet have modified the methods of keeping documentation and showing it to the public systems interested. Reservation systems, together with audiovisual documents and planimetry or cartography, have been catalogued and recorded in more flexible and quicker platforms to interact with research agents. However, the religious architecture, with big monuments that contain artistic works, requires a methodology that includes, at a structural and interoperative level, all the movable assets that can be catalogued. Cataloguing records are essential in religious buildings containing artistic works, including painting, sculpture, silverware objects, masonry, planimetry, bibliographical volumes and the building itself. Both cathedrals and churches are large containers that put in order the geometry of the elements, the symmetry and the order, and keep the emblematic work of archives, libraries and museums as the cultural centre of artistic dissemination.

Table 3 shows the process followed within the framework of this research work to include movable assets already catalogued in the HBIM project (under the umbrella of the National Heritage Institute of Equator). This document [58] includes the singularity of the systematic process that details the applications and reach of the recording, inventory and cataloguing processes.

An HBIM project constitutes recording both the 3D geometry and the information related to artistic works. Thus, the heritage site of the Church of the Company of Jesus in Quito is a good example to apply an HBIM project to art assets. This work focuses on developing, step by step, a semantically enriched digital model, from accurate data acquisition to the creation of a container of art assets. The digital management information system created can be a container of sustainability to specify public conservation, preservation and safeguarding policies of heritage assets. However, in this sustainability system, BIM operators consider the level of definition and development to achieve an appropriate cataloguing definition. The information of the agents is interoperated by indicating the LOD. This term is in linear progression on the amount of information of the modelled elements that are part of BIM [57], so the definition of the model has proportional geometric and semantic meanings. These levels are actually Levels of Details (LoDs) [59] and deepen the definition of the model. However, Bruno et al. [10] made a difference between LOD 
and LoD. Regarding the sustainability level of the digital integration system for movable and immovable heritage, the LODs of the models should be useful as a database for all the operators of the project.

Table 3. This table describes in detail the applications and reach of the processes.

\begin{tabular}{ccc}
\hline Recording & Inventory & Cataloguing \\
\hline $\begin{array}{c}\text { Identifies tangible and } \\
\text { intangible cultural assets. }\end{array}$ & $\begin{array}{c}\text { Describes the assets with a } \\
\text { heritage assessment, and } \\
\text { therefore exceptional values } \\
\text { that should be protected, kept, } \\
\text { and disseminated. }\end{array}$ & $\begin{array}{c}\text { Studies more in detail the } \\
\text { inventorying assets through } \\
\text { historical, iconographic, } \\
\text { architectural, anthropological, } \\
\text { and ethnographic studies, } \\
\text { among others. }\end{array}$ \\
$\begin{array}{c}\text { Refers to the cultural universe } \\
\text { of the country. }\end{array}$ & $\begin{array}{c}\text { Specifies the universe of the } \\
\text { CH of the country. }\end{array}$ & $\begin{array}{c}\text { Documents heritage assets in } \\
\text { a scientific, systemic and } \\
\text { methodological way. }\end{array}$ \\
\hline $\begin{array}{c}\text { Establishes the conservation } \\
\text { state of tangible cultural } \\
\text { assets and safeguards the } \\
\text { intangible CH. }\end{array}$ & $\begin{array}{c}\text { Details the vulnerability and } \\
\text { threat state of the tangible and } \\
\text { intangible assets of the CH } \\
\text { related to natural and human } \\
\text { risks. }\end{array}$ & $\begin{array}{c}\text { Inventory applications } \\
\text { Recording applications }\end{array}$ \\
$\begin{array}{c}\text { Geospatial location of cultural } \\
\text { assets in the territory. }\end{array}$ & $\begin{array}{c}\text { Referential documentation for } \\
\text { records. Elaboration of } \\
\text { thematic maps. Digital } \\
\text { cartography of heritage. }\end{array}$ & $\begin{array}{c}\text { Referential documentation for } \\
\text { records. Elaboration of } \\
\text { thematic maps. Digital } \\
\text { cartography of heritage. }\end{array}$ \\
\hline $\begin{array}{c}\text { Reference basis line } \\
\text { of the heritage in tangible and } \\
\text { intangible scopes. }\end{array}$ & $\begin{array}{c}\text { Information tool to manage } \\
\text { the CH of Decentralised } \\
\text { Autonomous Governments. }\end{array}$ & $\begin{array}{c}\text { Information tool to manage } \\
\text { the CH of Decentralised } \\
\text { Autonomous Governments. }\end{array}$ \\
\hline
\end{tabular}

In the case study, the HBIM project was based on the value provided by the point clouds, both for the information given by the textured geometry and its support to the appropriate structure of levels and to a system of accurate axes, which were required to reconsider the BIM model. The novelty of the developed process is that semantic data related to the movable object could be managed before the works of the parametric modelling of the architectural container. The accurate location of the asset, provided by the textured point cloud, was enough to locate a parametric object with accurate dimensions that could be identified in the HBIM project. Afterwards, the HBIM project was in a basic LOD (LOD100), where the point clouds defined the conceptual elements of the architectural and artistic heritage. This initial level progressively increased to define the parametric element graphically, specifying the size, the form, the quantities and the location of the site. In the modelling phase, the process of the connection of the elements to the point cloud or Level of Accuracy (LOA) was defined according to the guide published by the US Institute of Building Documentation (USIBD), as well as the specific data about the knowledge of the system of the object (geometric, structural and tangible) known as Level of Knowledge (LK), in line with the terminology provided by the Italian Technical Standards for Construction (Italian NTC 2009) [27].

\subsection{Methodology Applied to Identify the Artistic Assets}

Large amounts of information from the TLS surveys were managed, so two methods could be analysed and applied to identify artistic and historical assets: the segmentation of point clouds in strategic sectors as a classification methodology of the pieces, and a second method that related the data subset to a parametric object (based on the Geometric Descriptive Language (GDL) programming). The vestry was chosen as the most representative space of the church. This room contains many baroque elements and a varied set of artistic 
works. First, the point cloud was segmented in areas to delimit the scanned paintings. This procedure was effective outside the HBIM digital platform, and point cloud management software, such as Cloudcompare or Cyclone Register 360 from Leica, was required for implementation. It must be taken into account that the point cloud needs to provide an adequate resolution for monitoring. The Leica BLK360 scanner, with Waveform Digitizing (WFD) technology, has three HDR digital cameras, a colour sensor and fixed focal length (Image $2592 \times 1944$ pixels) and one Infrared thermal camera (Image $160 \times 120$ pixels), with four integrated within the team. Although the laser system of the equipment reaches a precision of range $4 \mathrm{~mm}$ to $10 \mathrm{~m}$, the "High density" mode, used in all surveys, provides a resolution of $5 \mathrm{~mm} @ 10 \mathrm{~m}$ (distance is not exceeded). Therefore, techniques such as the Structure from Motion/Multiview-Stereo (SfM/MVS) could be more appropriate because other inherent properties of the MDC system were available. However, the TLS system gives us 360 panoramas (full dome of 30 images, $150 \mathrm{Mpx}, 360^{\circ} \times 300^{\circ}$ ), very suitable to be explored from the JetStream application, allowing three Image options-colour, HDR and IR (Figure 9). In this regard, all the paintings in the vestry were identified with limit boxes (Box limit from Cyclone). These boxes could be managed and exported to an original format of Leica for analysis (Figure 10), although outside of the BIM environment.

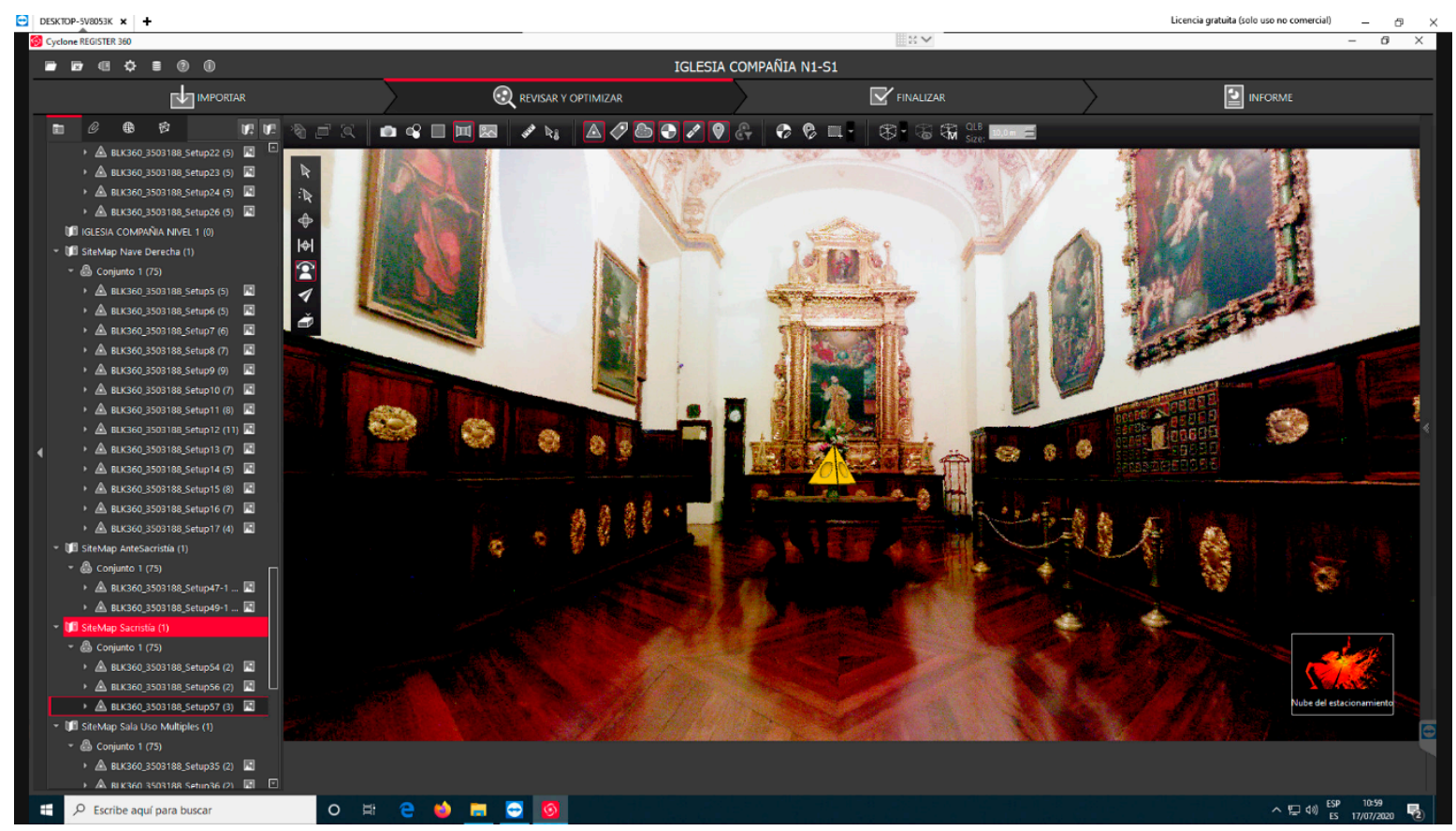

Figure 9. Exploration and management of the scans of the Church of the Company of Jesus with Leica Cyclone Register 360. Sitemap of the vestry to be exported.

The second method consisted of locating parametric objects without using tools of constructive systems, i.e., Wall or Form, that are appropriate. Although both were appropriate to be later mapped with an appropriate texture, their use could modify their standard classification. For this purpose, the Picture object (based on GDL programming) with accurate dimensions in the chart was used: it was more flexible as it included a parameter to link an image adapted to the size established. All charts were modelled with the actual dimensions taken from the point cloud and were mapped with a high resolution orthoimage. These objects accrued great benefits for the conservation management as they were linked to specific parameters for recording and cataloguing the artistic asset. 


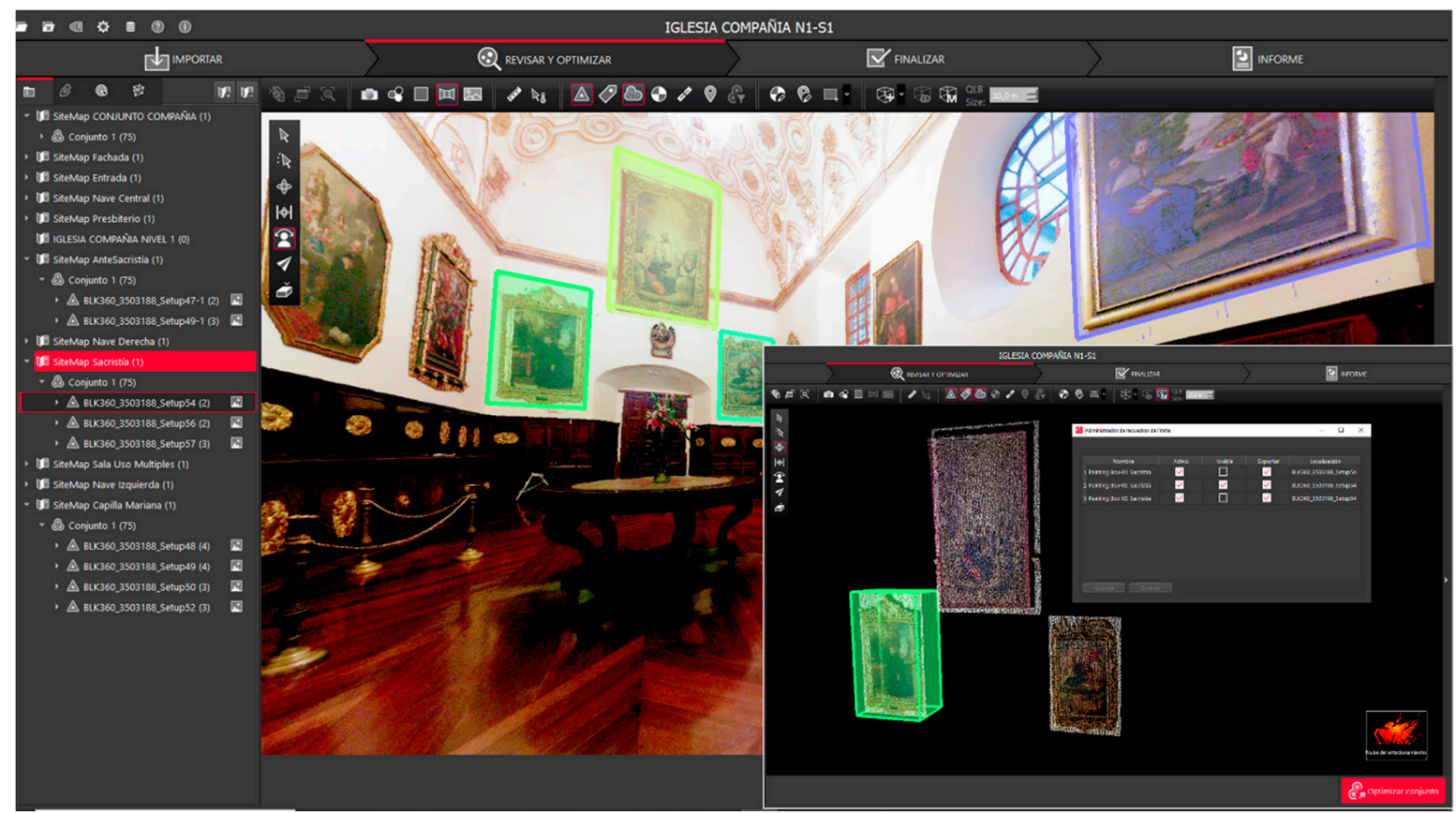

Figure 10. Identification and segmentation of the paintings in the vestry using Box limit from Cyclone Register 360.

\subsection{Database of the Movable Assets}

The BIM platform usually associates objects in the dialogue charts with usual property categories related to the construction material, identification and manufacture, although other specific functions could be included. Thus, the three processes (recording, inventory and cataloguing) are essential in the HBIM project. The property administer from ArchiCAD was used to create and administer the heritage property set. However, the characteristic items considered in the recording and inventory sheets of movable assets, published by the National Heritage Institute (NHI) of Equator, were compiled. Thus, values were defined by each type, and the availability of properties for several classifications were personalised. Consequently, when a parametric object was edited in the HBIM project, an editing subwindow of a new category called Heritage Furniture was available. To define a damage analysis of the movable object, an Option Set type was programmed as it facilitated a numerous selection that defined the variables of the objects (Figure 11).

These characteristics are related to the conservation and maintenance of the works of art, including marks, loosening, rips, deformations and overpainting. After recording the artistic assets of the vestry, specific labels were created with the specific data for a rapid graphic identification of the objects within the HBIM project. The properties of these labels could be modified by accessing the pre-established options in the Classification and Properties section of the Picture object. Thus, the state of vulnerability, the heritage assessment, the characteristics and values of the work of art established by the specialist were shown (Figure 12).

\subsection{The Interoperability of Data with the Specialists in Conservation and Restoration}

For the conservation works of the art assets of the Church of the Company of Jesus, the specialist in restoration of the TeamWork-HBIM team provided all the information included in the recording sheet of the NHI, including the historical references and conservation data of the asset, such as the incorporation of items in the damage analysis. The process was based on the work by Bienvenido et al., 2019 [25], who established charts of reintegration elements (i.e., the tiles of the Pavilion of Charles V from the 16th century) in the HBIM project with appropriate classification items for restoration work, stressing the variables that classify the degree of intervention (state of conservation, adherence to the support, chromatic reintegration and volumetric reintegration) and were complemented 
by the expert. The TeamWork-HBIM team collaborated with external agents, so the interoperability of the workflow was solved by exporting the sheets to Excel tables (.xlsx). Thus, the restorer of the Foundation of the Church of the Company of Jesus could fill the items of the auscultation with the variables previously established (Figure 11). Four options could be chosen for the degree of conservation: excellent, okay, regular and bad. Moreover, the options of tears, stains, marks, fractures, ripped, folds, burns, loosening, insects, deformations, etc. (up to 26 options) could be chosen in the damage analysis. Afterwards, the complete and reviewed tables were imported into the HBIM project, and all data were automatically updated. Thus, the process was very sustainable as the collaborative workflow was reinforced, both inside and outside the TeamWork team (Figure 13).

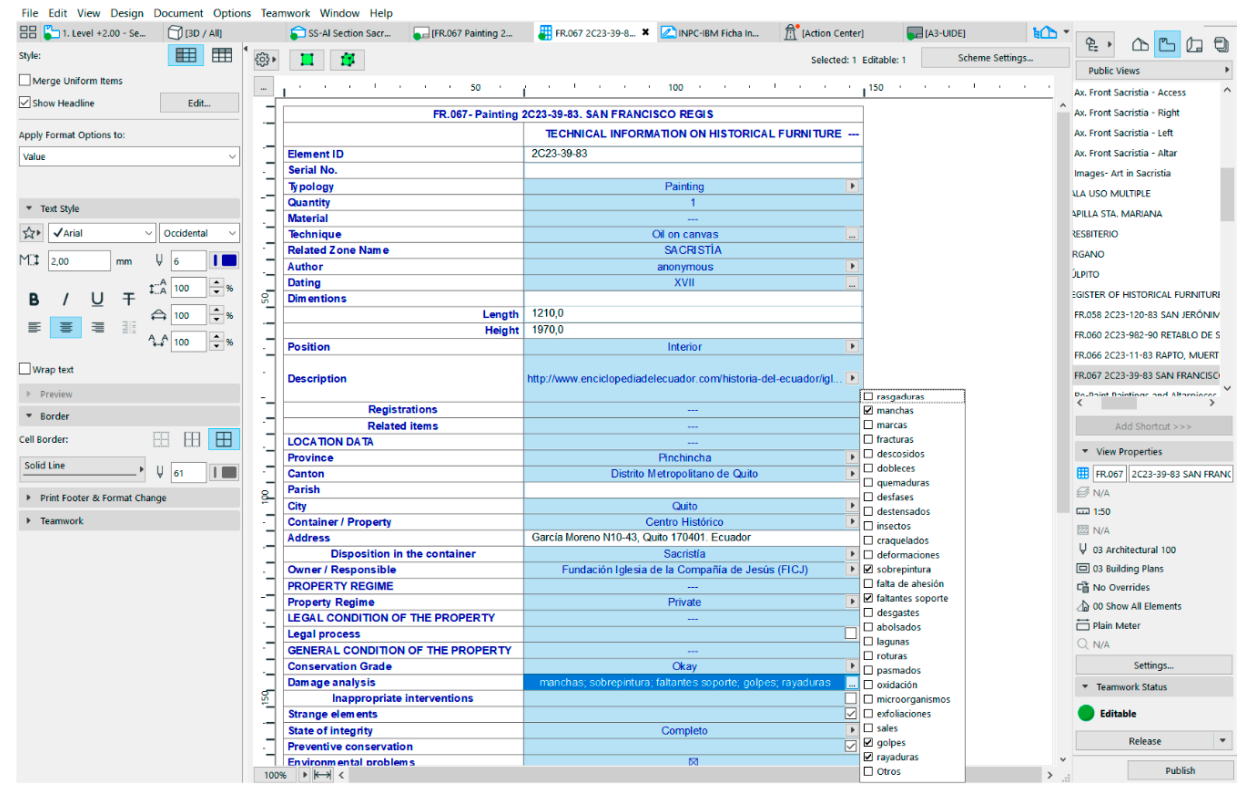

Figure 11. Scheme edition of the HBIM project. Definition of the damage analysis of the Painting object with an Option Set type.

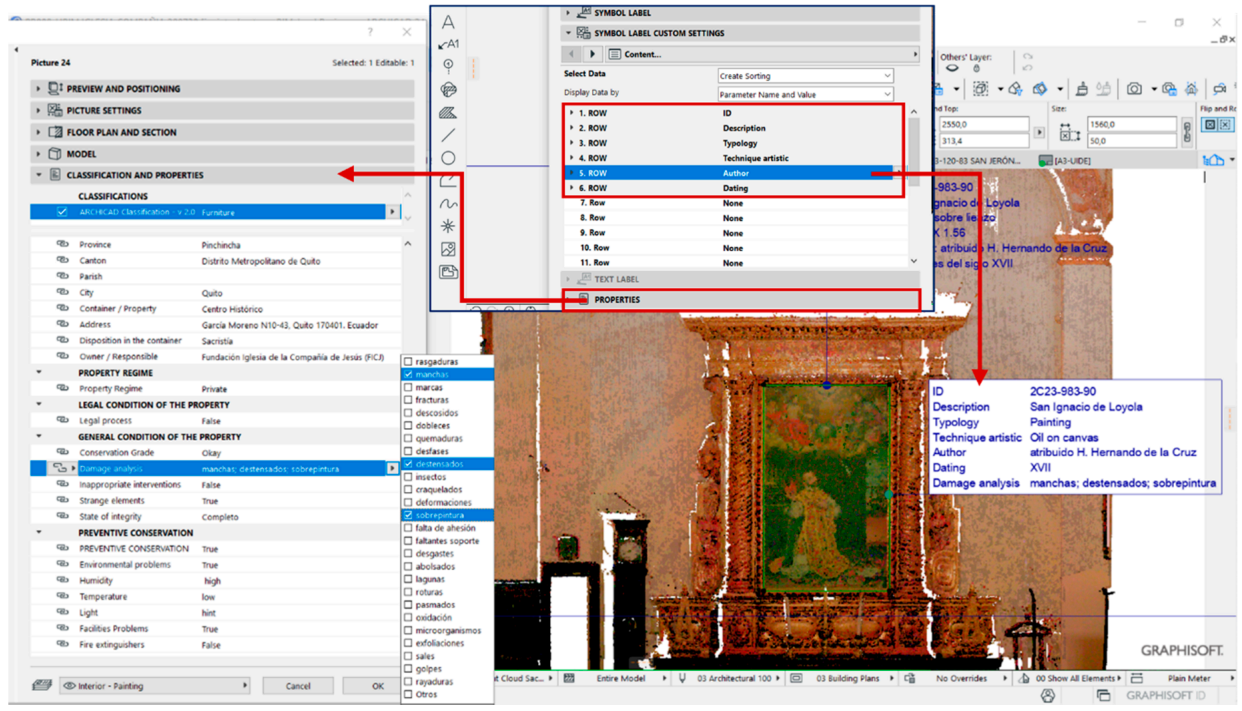

Figure 12. Labelling of the paintings of the vestry and edition of the properties included in the labels of the Picture object according to the pre-established options from the Classification and Properties section. 


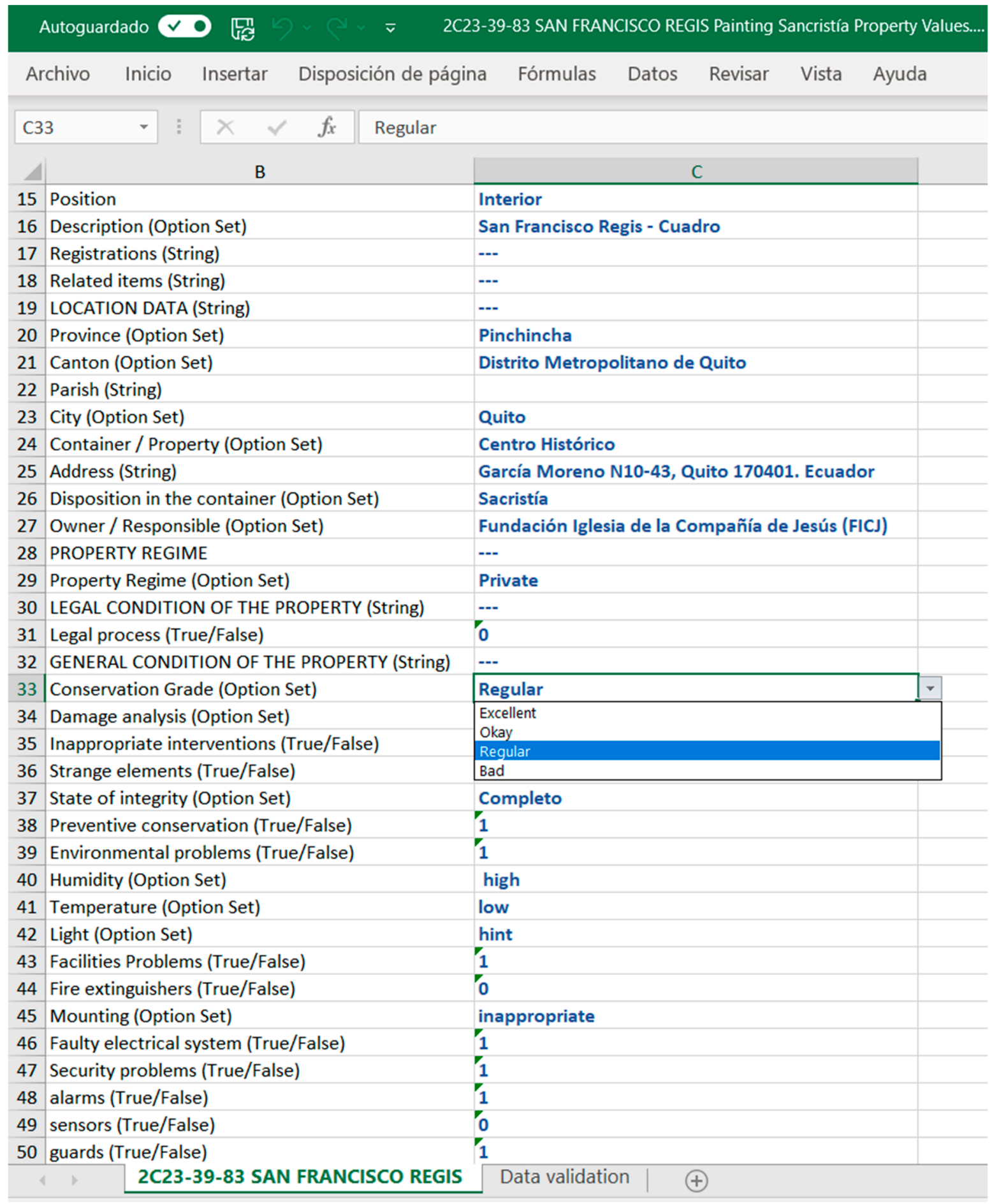

Figure 13. Excel table exported, with the items established in the scheme of the recording sheet. The restorer will review and complement the properties according to the auscultation. The document will be imported into the HBIM project again, and data will be automatically updated.

\subsection{Creation of Recording and Inventory Sheets}

To record and quantify the objects, various tables of the elements catalogued by the HBIM project were created by using a configuration of the Scheme of ArchiCAD for each artistic category. Finally, the recording and inventory sheets of both the paintings in oils and the main altarpiece of the vestry were obtained. The sheet of a painting included the scheme 
with all the properties items of the Heritage Furniture category (according to the model of the NHI sheet): the plan with the identification of the object, a general elevation of the point cloud with the painting labelled and the orthoimages for the appropriate auscultation (Figure 14a). As a complement to a better auscultation of an artistic set, such as the altarpiece of San Ignacio de Loyola and the paintings in oils, the sheet included images from the 360-HDR exploration taken by the scanner equipment. A link to the JetStream application was created; this application was included in the CDE of the collaborative project to be easily explored by the specialist (Figure 13). Thus, to record and catalogue the art objects in an HBIM project, the orthoimages and the range cloud were accurate enough to monitor each artistic category.

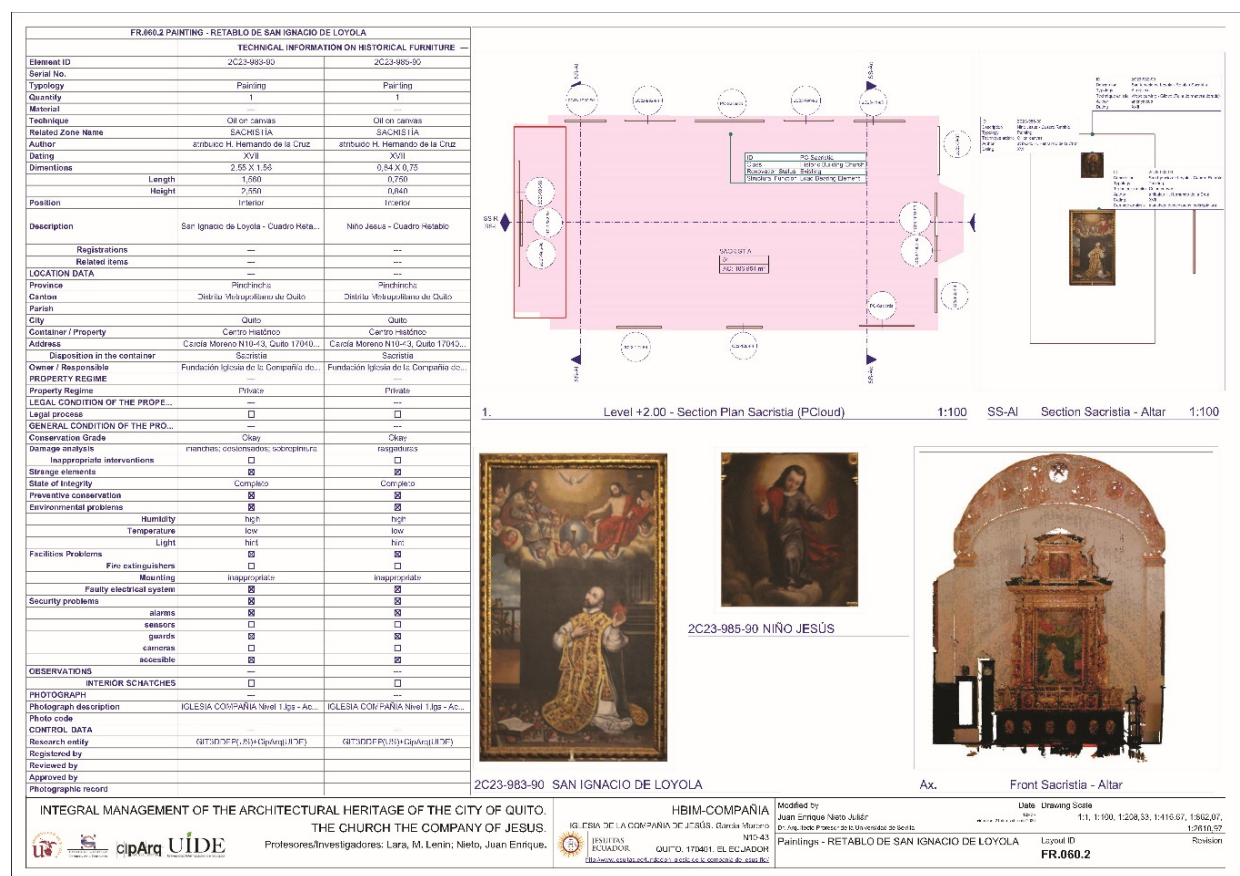

(a)

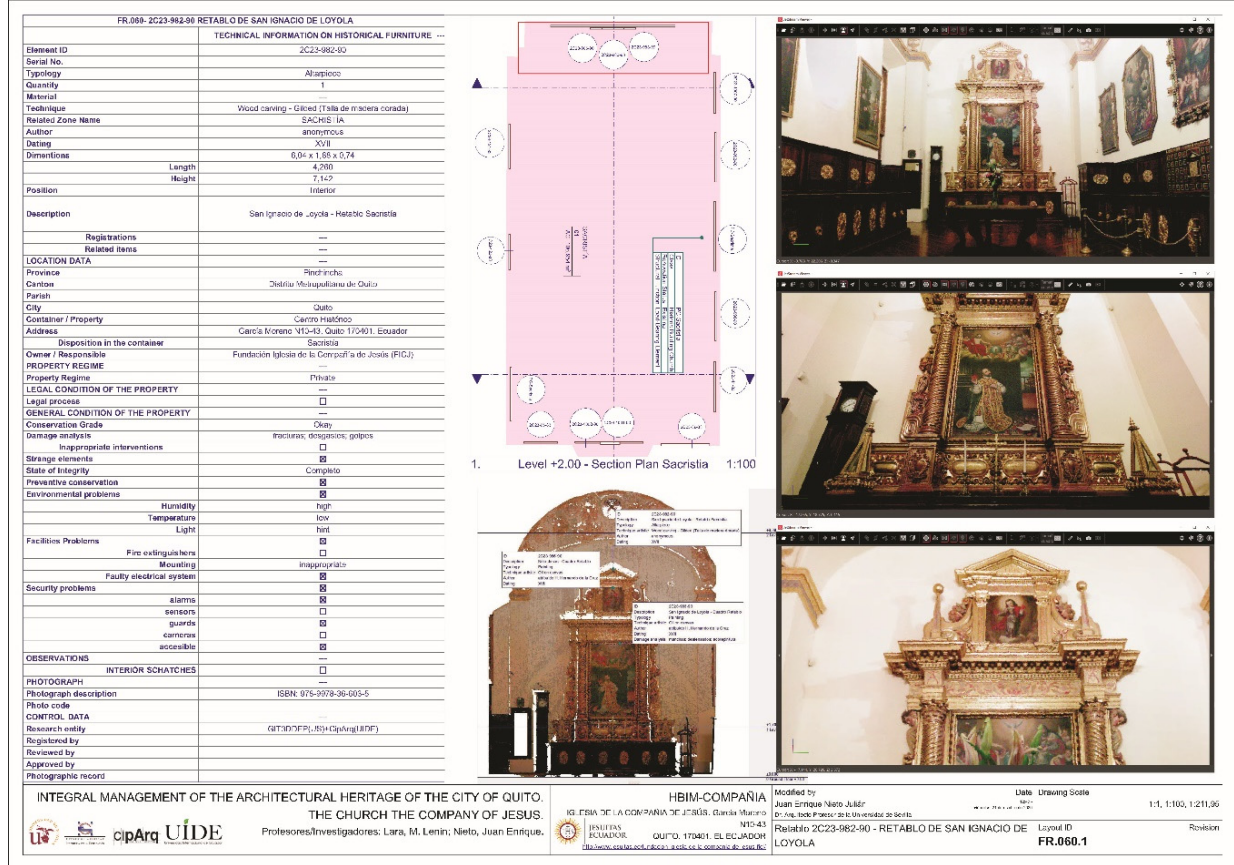

(b)

Figure 14. (a) Recording sheet of the altarpiece of San Ignacio de Loyola; (b) recording sheet of the paintings in oils included. 
Thus, the TeamWork + CDE platform could be used by the BIM operators to create accurate parametric models that reproduce the artistic assets, based on the range cloud included in the HBIM project. As a general inventory sheet of the vestry, a scheme was configured with all the properties of the Heritage Furniture category by following the model of the NHI sheet. All the information compiled was linked to a rich database that is continuously updated (Figure 15).

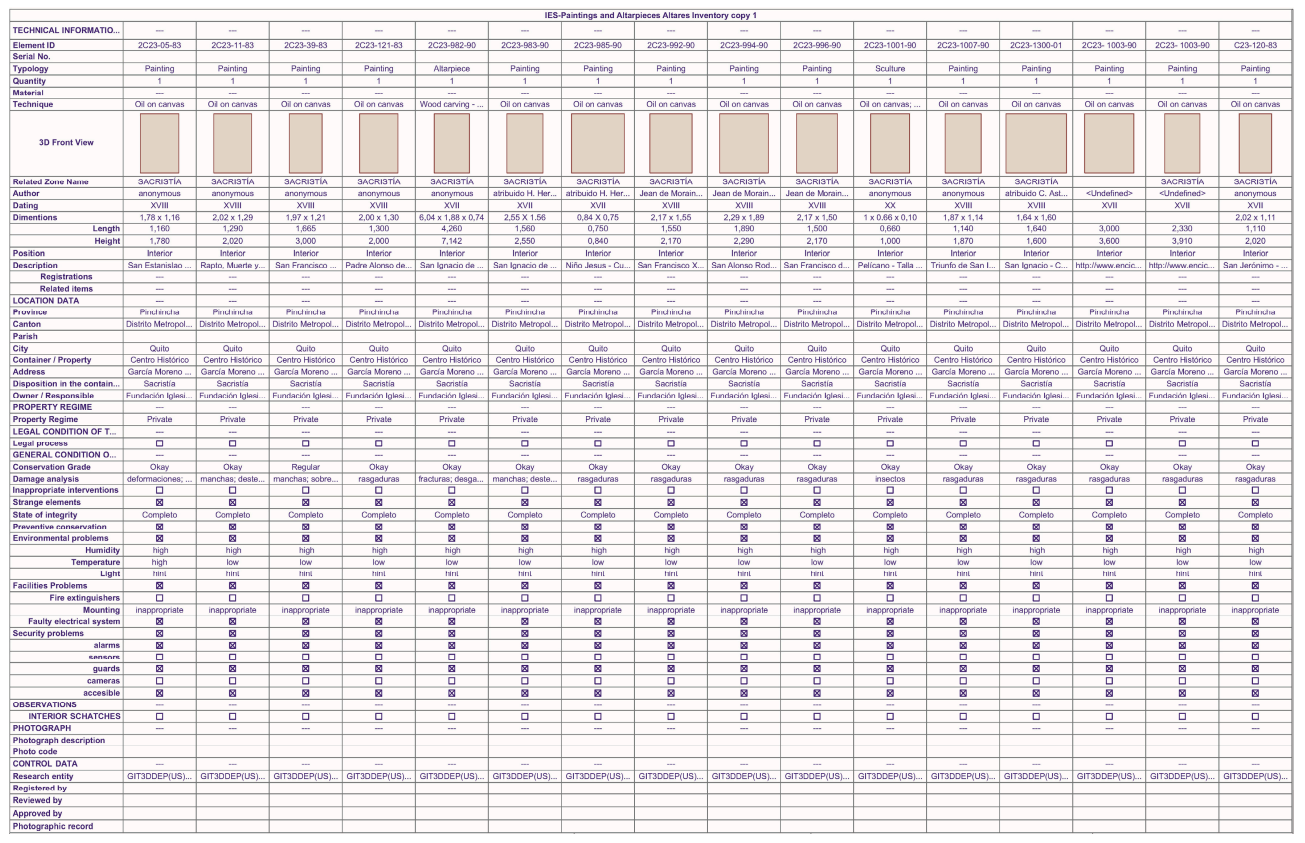

Figure 15. General sheet of the paintings recorded in the vestry. A specific scheme of ArchiCAD with all the Properties items from the Heritage Furniture category was configured according to the National Heritage Institute (NHI) sheet.

By way of a summary, the following scheme (Figure 16) shows the influx of information within a sustainable interoperability process in TeamWork-HBIM-CDE.

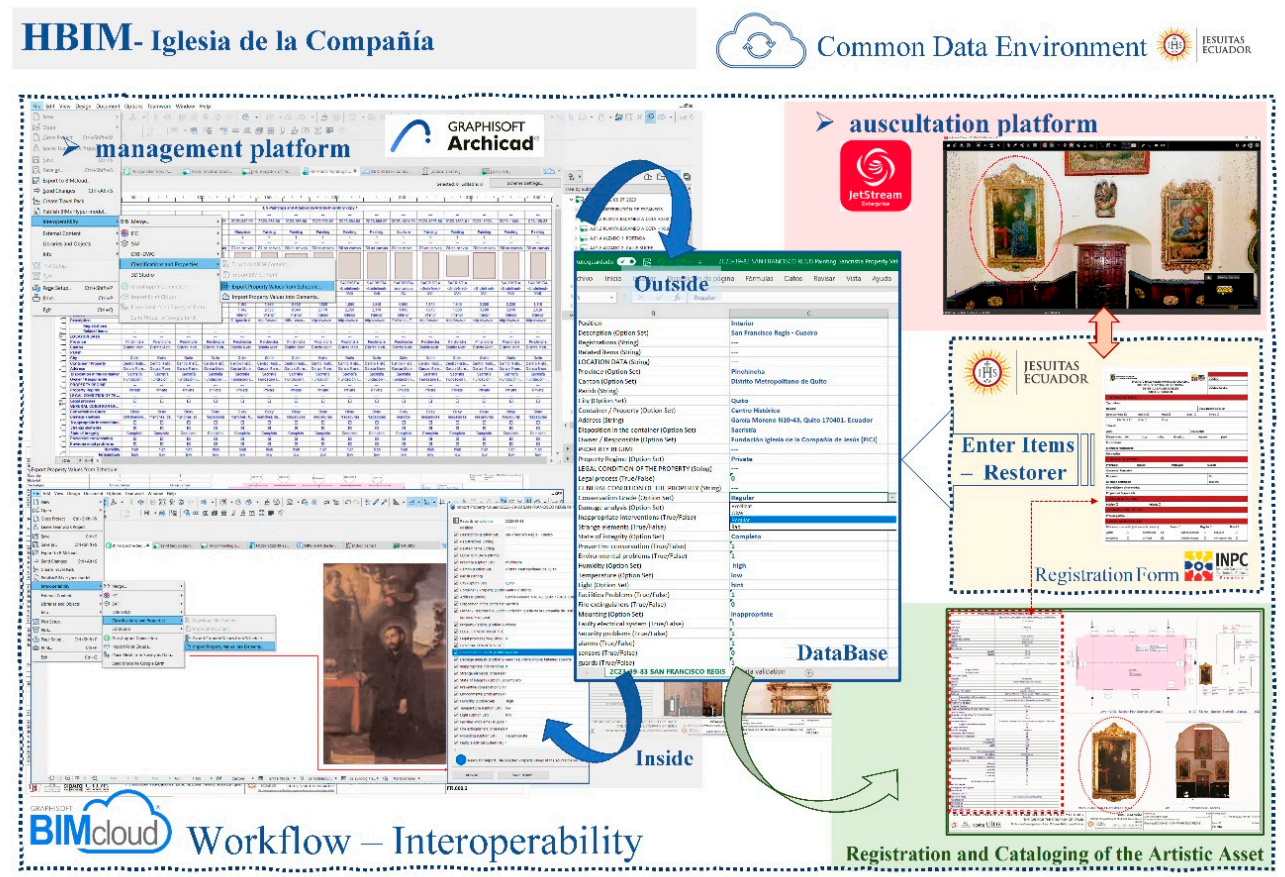

Figure 16. Graphic of the workflow interoperability in a TeamWork-HBIM-CDE. 


\section{Discussion}

The cataloguing of movable and immovable assets today is crucial. Cataloguing is valued as the agent in the process of making technology and scientific progress in the scope of heritage. The systematic processes including the creation of inventories require procedures that simplify the integration of a large database into an information digital model. The process presented in this paper is part of the development and implementation of an integral system to manage $\mathrm{CH}$. It consists of acquiring historical, artistic and architectural information of many buildings, together with urban, constructive and pathology information. Thus, significant field work to examine and inspect buildings is required, as well as the location of their planimetry information, the obtaining of accurate graphic information, and the making of conservation proposals. Finally, a synthesis and classification report of intervention priorities is available and could be monitored by cities, provinces or autonomous territories of the country.

The method applied to the case study was used to obtain the maximum profitability of the initial remote sensing techniques by effectively managing the information provided by the scans and the photogrammetry before acquiring a three-dimensional model of the parametric elements. One of the aspects of the system was the reliability of the structure of the HBIM project. The parametric model was based on a distribution of levels and a network of axes appropriate for the actual geometry of the building provided by the point clouds. The information was valid in the virtual auscultation for both the modelling works and the specialists in restoration. In addition, the metadata of the scans and the postprocessing were included both in reports approved and linked to the HBIM project and in the database of the CDE. It was important that this information, before the segmentation, was available for subsequent works, mainly for processing a new survey. The BIM software is today limited to manage large point cloud files because of the large amount of information provided by scans; however, these disadvantages should be solved in the future.

The methodology was thus strengthened because many essential disciplines of $\mathrm{CH}$ conservation were included in the project. The HBIM project met the needs of the Foundation of the Church of the Company of Jesus regarding documentation inventory, data management and conservation activities planned by the multidisciplinary service (architects, engineers, historians, art restorers and heritage disseminators). Every coworker from the TeamWork-HBIM team dcould access a BIMcloud server and intervene according to their role and permission given. As an operative CDE was also established as a support for the HBIM project, the method facilitated other actors and external specialists in auscultating the artistic assets appropriately-identifying, recording, quantifying, consulting and referencing pieces and constructive systems of the model for the continuous conservation and sustainability of the historic building. The use of the interface of the BIM platform to identify the artistic asset, together with the ease with which the restorer could include the values related to the studies, turned the process into a powerful and effective tool. The system also included $360^{\circ}$ viewers to fully include the point cloud of the building, thus capturing its characteristics and measurements. In works of recording or making reports before an intervention, specialists could explore $360^{\circ}$ panoramic (HDR, IR) images and obtain accurate metric information directly from the point clouds, without considering the 3D simply parametrised representations or those including an inappropriate LOD due to the geometric simplifications. This functionality is also valid for the benefit of governmental institutions when managing the asset and disseminating it to the public because all the updated information of the building related to its conservation cycle could be accessed. The system therefore provided an appropriate and personalised interface linked to the parametric model classified, thus facilitating the introduction of appropriate data to intervene the artistic or architectural piece. In addition, the BIM model continuously updates the parameters.

Within this context of sustainability, the project is being worked on by developing parametric models based on the HBIM structure, which is created by the data provided by the surveys. Especially, the usual methodology can be improved by providing greater 
effectiveness and productivity in the processes from scan to BIM. However, it is true that a more effective interoperability is required for the workflow presented. Communication problems should be solved, particularly in the operativity of the information centralised in the CDE; moreover, the access protocol should be improved to speed up the access. The accessibility to data by other external researchers through a graphic exploration of the model required greater fluidity. Open BIM should also be reinforced by transmitting data to the open standard format (Industry Foundation Classes (IFCs)) considering the characteristics of the building. Data reciprocity is not a worrying aspect because the latest advances in the AEC industry facilitate the sharing of information among many specific software; however, there is no established common classification of constructive systems and historical pieces, which are not usual in the current construction but essential to manage heritage assets.

\section{Conclusions}

This document justifies the theory of generating an HBIM model in a digital platform that is sustainable for cultural heritage. The sustainability showed by the collaborative TeamWork-HBIM working system under the umbrella of a CDE presents objectives related to the integral management in heritage research, preservation, restoration and dissemination. This paper includes the first interventions in a representative heritage of Quito within an integrated heritage management project of the city. The implementation of a sustainable conservation plan for a historic building for the conservation of a rich heritage site, such as the Church of the Company of Jesus, is a work requiring time not because of the assimilation of concepts and the skill acquisition in using digital tools to represent and manage information, but because of the change of professional relationships and traditional work methodologies. Research and experimentation should be included to the usual preservation, restoration and dissemination works, considered from several disciplinary perspectives. The new HBIM project should ensure interoperability from various sides, including specialists of the technician team in intervention, maintenance and conservation, as well as tourist managers. For this purpose, the Heritage-CDE should be the only source of information of a sustainable collaborative project to compile and manage graphic documentation in the HBIM project, including the point clouds, the parametric models and metadata-i.e., all the information of the project should be both in a valid format, (whether in BIM or in a conventional and complementary data format) for the whole teamwork and property, and accurate, to disseminate the heritage value.

This is therefore a crucial moment to define the terms to implement a full database that includes all the artistic and architectural pieces of a historic building. In the future, we have to develop georeferencing applications through a Global Navigation Satellite System (GNSS) or Total Station (TS) to createe a reference frame in order to accurately monitor a building over time. The workflow should include metadata, which are progressive scientific and academic contributions; moreover, the workflow should be flexible and effective regarding the accessibility and enrichment of information in the consecutive conservation phases.

The method proposed is new because it raises the profitability of the initial remote sensing techniques work before increasing the Level of Development of a complete threedimensional model of heritage parametric elements. The project was effectively structured according to the actual geometry and, in an early stage of the HBIM project, specific data were related to the point clouds segmented. In this regard, GDL parametric objects were accurately placed as these objects include the actual image of the artistic asset for a correct auscultation. The specialist could fill in the essential data and the anomalies were easily detected considering the items of artistic, historic and conservation properties and choosing among the predetermined options. Complete sheets including schemes for recording, measuring and cataloguing all the artistic assets located in that container were created. In addition, the sheets were personalised to adapt them according to the National Heritage Institute in Equator. 
Afterwards, this process will continue with new effective works, such as facilitating the modelling works that are accurate to the existing architecture, essential for future studies related to the structural, energy, budgeting and maintenance aspects. The BIM technology allows data to be interoperated among specific software, thus easing the collaboration between the disciplines of the architecture, engineering and construction (AEC) sector. An aspect of the HBIM project lies in the structural analysis and the decision-making of engineers and restorers before restoring or strengthening the conservation process. The city of Quito, located in the skirt of the Pichincha Volcano and on a system of faults, has been harmed throughout the centuries by a wide seismic and volcanic activity (the documented first earthquake took place in 1541) [60], but the earthquakes in 1755, 1797, 1859 and 1868 caused more damage [61]; thus, the specialist needs these BIM experimentation models to support the seismic studies of cause and effect. Many advantages for the conservation actions are provided by the BIM collaborative methodology. For this purpose, to tackle the complexity of cultural heritage, an effective and progressive use by the AEC professionals and a greater implication of public or private institutions, which protect cultural heritage assets, would be essential to implement effective systems such as HBIM.

Author Contributions: The contribution of the authors is as follows: Conceptualization, J.M. and J.E.N.-J.; methodology, J.M. and J.E.N.-J.; software, J.E.N.-J.; validation, J.M. and J.E.N.-J.; formal analysis, J.M. and J.E.N.-J.; investigation, J.M. and J.E.N.-J.; resources, L.L. and J.E.N.-J.; data curation, J.M. and J.E.N.-J.; writing-J.M. and J.E.N.-J.; writing-review and editing, J.M. and J.E.N.-J.; visualization, J.M. and J.E.N.-J.; supervision, J.M.; project administration, J.E.N.-J. and L.L. All authors have read and agreed to the published version of the manuscript.

Funding: This research was funded by the Directorate-general for Research and Postgraduate Studies, International University of Ecuador, within the Research Residence UIDE 2019 program. It is related to the Integrated Management System for the Architectural Heritage of the City of Quito project, which is run by the architect D. Juan Enrique Nieto and supported by the School for the City, Landscape and Architecture (UIDE).

Institutional Review Board Statement: Not applicable.

Informed Consent Statement: Not applicable.

Data Availability Statement: All data, models, and code generated or used during the study appear in the submitted article.

Acknowledgments: We acknowledge the Foundation of the Church of the Company of Jesus, and particularly the director, the architect Diego Santander, for facilitating the human and technical means to ensure the high quality of this work, particularly in the in situ scanning phase.

Conflicts of Interest: The authors declare no conflict of interest. The funders had no role in the design of the study; in the collection, analyses, or interpretation of data; in the writing of the manuscript, or in the decision to publish the results.

\section{References}

1. Stober, D.; Žarnić, R.; Penava, D.; Turkalj Podmanicki, M.; Virgej-Đurašević, R. Application of HBIM as a Research Tool for Historical Building Assessment. Civ. Eng. J. 2018, 4, 1565. [CrossRef]

2. Al-Sakkaf, A.; Zayed, T.; Bagchi, A.; Mahmoud, S.; Pickup, D. Development of a sustainability rating tool for heritage buildings: Future implications. Smart Sustain. Built Environ. 2020. [CrossRef]

3. Khodeir, L.M.; Aly, D.; Tarek, S. Integrating HBIM (Heritage Building Information Modeling) Tools in the Application of Sustainable Retrofitting of Heritage Buildings in Egypt. Procedia Environ. Sci. 2016, 34, 258-270. [CrossRef]

4. Reinoso-Gordo, J.F.; Rodríguez-Moreno, C.; Gómez-Blanco, A.J.; León-Robles, C. Cultural Heritage conservation and sustainability based on surveying and modeling: The case of the 14th century building Corral del Carbón (Granada, Spain). Sustainability 2018, 10, 1370. [CrossRef]

5. Yilmaz, H.M.; Yakar, M.; Gulec, S.A.; Dulgerler, O.N. Importance of digital close-range photogrammetry in documentation of cultural heritage. J. Cult. Herit. 2007, 8, 428-433. [CrossRef]

6. Jordan-Palomar, I.; Tzortzopoulos, P.; García-Valldecabres, J.; Pellicer, E. Protocol to manage heritage-building interventions using heritage building information modelling (HBIM). Sustainability 2018, 10, 908. [CrossRef] 
7. Salam, N.F.A. HBIM-A Sustainable Approach for Heritage Buildings Restoration in Egypt. IOP Conf. Ser. Earth Environ. Sci. 2020, 410, 012072. [CrossRef]

8. Fadli, F.; AlSaeed, M. Digitizing vanishing architectural heritage; The design and development of Qatar historic buildings information modeling [Q-HBIM] platform. Sustainability 2019, 11, 2501. [CrossRef]

9. Fonnet, A.; Alves, N.; Sousa, N.; Guevara, M.; Magalhães, L. Heritage BIM integration with mixed reality for building preventive maintenance. In Proceedings of the EPCGI 2017-24th Encontro Portugues de Computacao Grafica e Interacao, Guimaraes, Portugal, 12-13 October 2017; Institute of Electrical and Electronics Engineers Inc.: Piscataway, NJ, USA, 2017; Volume 2017, pp. 1-7.

10. Bruno, S.; De Fino, M.; Fatiguso, F. Historic Building Information Modelling: Performance assessment for diagnosis-aided information modelling and management. Autom. Constr. 2018, 86, 256-276. [CrossRef]

11. Simeone, D.; Cursi, S.; Acierno, M. BIM semantic-enrichment for built heritage representation. Autom. Constr. 2019, 97, 122-137. [CrossRef]

12. Di Mascio, D.; Pauwels, P.; De Meyer, R. Improving the knowledge and management of the historical built environment with BIM and ontologies: The case study of the Book Tower. In Proceedings of the 13th International Conference on Construction Applications of Virtual Reality, London, UK, 30-31 October 2013.

13. Crofts, N.; Doerr, M.; Gill, T.; Stead, S.; Stiff, M. Definition of the CIDOC Conceptual Reference Model. Available online: http://www.cidoc-crm.org/docs/cidoc_crm_version_5.0.2.pdf (accessed on 3 November 2020).

14. Acierno, M.; Cursi, S.; Simeone, D.; Fiorani, D. Architectural heritage knowledge modelling: An ontology-based framework for conservation process. J. Cult. Herit. 2017, 24, 124-133. [CrossRef]

15. Tang, P.; Huber, D.; Akinci, B.; Lipman, R.; Lytle, A. Automatic reconstruction of as-built building information models from laser-scanned point clouds: A review of related techniques. Autom. Constr. 2010, 19, 829-843. [CrossRef]

16. Thomson, C.; Boehm, J. Automatic geometry generation from point clouds for BIM. Remote Sens. 2015, 7, 11753-11775. [CrossRef]

17. Wang, C.; Cho, Y.K.; Kim, C. Automatic BIM component extraction from point clouds of existing buildings for sustainability applications. Autom. Constr. 2015, 56,1-13. [CrossRef]

18. Andriasyan, M.; Moyano, J.; Nieto-Julián, J.E.; Antón, D. From Point Cloud Data to Building Information Modelling: An Automatic Parametric Workflow for Heritage. Remote Sens. 2020, 12, 1094. [CrossRef]

19. Library, P.C. Point Cloud Library I The Point Cloud Library (PCL) Is a Standalone, Large Scale, Open Project for 2D/3D Image and Point Cloud Processing. Available online: https:/ / pointclouds.org/ (accessed on 7 January 2021).

20. Pierdicca, R.; Paolanti, M.; Matrone, F.; Martini, M.; Morbidoni, C.; Malinverni, E.S.; Frontoni, E.; Lingua, A.M. Point Cloud Semantic Segmentation Using a Deep Learning Framework for Cultural Heritage. Remote Sens. 2020, 12, 1005. [CrossRef]

21. Malinverni, E.S.; Pierdicca, R.; Paolanti, M.; Martini, M.; Morbidoni, C.; Matrone, F.; Lingua, A. Deep learning for semantic segmentation of 3D point cloud. gs. In Proceedings of the The International Archives of the Photogrammetry, Remote Sensing and Spatial Information Sciences, Ávila, Spain, 1-5 September 2019; Volume XLII-2/W15, pp. 735-742.

22. Patrucco, G.; Chiabrando, F.; Dameri, A.; Losè, L.T. Geomatic contribution for the restoration project of the valentino castle green room. From data acquisition to integrated documentation. In Proceedings of the The International Archives of the Photogrammetry, Remote Sensing and Spatial Information Sciences, Nice, France, 31 August-3 September 2020; Volume XLIII-B2, pp. 885-892.

23. Moyano, J.; Odriozola, C.P.; Nieto-Julián, J.E.; Vargas, J.M.; Barrera, J.A.; León, J. Bringing BIM to archaeological heritage: Interdisciplinary method/strategy and accuracy applied to a megalithic monument of the Copper Age. J. Cult. Herit. 2020, 45, 303-314. [CrossRef]

24. Bruno, S.; Musicco, A.; Fatiguso, F.; Dell'Osso, G.R. The Role of 4D Historic Building Information Modelling and Management in the Analysis of Constructive Evolution and Decay Condition within the Refurbishment Process. Int. J. Archit. Herit. 2019, 1-17. [CrossRef]

25. Bienvenido-Huertas, D.; Nieto-Julián, J.E.; Moyano, J.J.; Macías-Bernal, J.M.; Castro, J. Implementing Artificial Intelligence in H-BIM Using the J48 Algorithm to Manage Historic Buildings. Int. J. Archit. Herit. 2019, 14, 1146-1160. [CrossRef]

26. Pocobelli, D.P.; Boehm, J.; Bryan, P.; Still, J.; Grau-Bové, J. Building information models for monitoring and simulation data in heritage buildings. In Proceedings of the The International Archives of the Photogrammetry, Remote Sensing and Spatial Information Sciences, Riva del Garda, Italy, 4-7 June 2018; Volume XLII-2, pp. 909-916.

27. Bruno, N.; Roncella, R. HBIM for Conservation: A New Proposal for Information Modeling. Remote Sens. 2019, 11, 1751. [CrossRef]

28. 10303-11, ISO. Industrial Automation Systems and Integration-Product Data Representation and Exchange; ISO: Geneva, Switzerland, 1994; 1_58.

29. Macher, H.; Landes, T.; Grussenmeyer, P. From point clouds to building information models: 3D semi-automatic reconstruction of indoors of existing buildings. Appl. Sci. 2017, 7, 1030. [CrossRef]

30. Diara, F.; Rinaudo, F. Open source hbim for cultural heritage: A project proposal. In Proceedings of the The International Archives of the Photogrammetry, Remote Sensing and Spatial Information Sciences, Riva del Garda, Italy, 4-7 June 2018; Volume 42, pp. 303-309.

31. Company, A.N. Product I dRofus. Available online: https://www.drofus.com/en/product (accessed on 11 January 2021). 
32. García-Valldecabres, J.; Pellicer, E.; Jordan-Palomar, I. BIM Scientific Literature Review for Existing Buildings and a Theoretical Method: Proposal for Heritage Data Management Using HBIM. In Proceedings of the Construction Research Congress 2016: Old and New Construction Technologies Converge in Historic San Juan, San Juan, Puerto Rico, 31 May-2 June 2016; pp. $2228-2238$.

33. Khanzadi, M.; Sheikhkhoshkar, M.; Banihashemi, S. BIM applications toward key performance indicators of construction projects in Iran. Int. J. Constr. Manag. 2020, 20, 305-320. [CrossRef]

34. Navarro, J.G. La iglesia de la Compañía de Jesús en Quito. Arquit. Am. 1928, 311-324. Available online: http://data. cervantesvirtual.com/manifestation/281416 (accessed on 20 January 2020).

35. Escudero Albornoz, X. Pulpitos Quiteños; TRAMA, Ed.; Biblioteca: Quito, Ecuador, 2016; ISBN 9978-43-662-6.

36. Schenone, H.H. Iconografia del Arte Colonial/1; Fundación Tarea: Buenos Aires, Argentina, 1992; ISBN 9879905318.

37. Escultura Colonial Quiteña: Arte y Oficio-Ximena Escudero-Albornoz-Google Libros. Available online: https://books.google. es /books?hl=es\&lr=\&id=KRHg58kcJvIC\&oi=fnd\&pg=PA17\&dq=Escudero, +X.+(2007).+Escultura +colonial+quite $\sim$ na, + arte + $\mathrm{y}+$ oficio,+Quito, +Imprenta+Mariscal.+\&ots=SCNrK8B1UX\&sig=WgIABGmBe8LNOsLzCoiwjhg5ooc\#v=onepage\&q\&f=false (accessed on 19 October 2020).

38. Kankare, V.; Puttonen, E.; Holopainen, M.; Hyyppä, J. The effect of TLS point cloud sampling on tree detection and diameter measurement accuracy. Remote Sens. Lett. 2016, 7, 495-502. [CrossRef]

39. Rebolj, D.; Pučko, Z.; Babič, N.Č.; Bizjak, M.; Mongus, D. Point cloud quality requirements for Scan-vs-BIM based automated construction progress monitoring. Autom. Constr. 2017, 84, 323-334. [CrossRef]

40. Lindstaedt, M.; Kersten, T.P.; Blaskow, R.; Schneider, D.; Kersten, T. Untersuchungen zum Genauigkeitspotential des terrestrischen Laserscanners Leica BLK360 Comparative Geometrical Investigations of Hand-held Scanning Systems (Update) View project Determination of Intensity-Based Stochastic Models for Terrestrial Laser Scanners Utilising 3D-Point Clouds View project Untersuchungen zum Genauigkeitspotential des ter-restrischen Laserscanners Leica BLK360. In Photogrammetrie, Laserscanning, Optische 3D-Messtechnik_Beiträge der Oldenburger 3D-Tage 2018, Th. Luhmann/Ch. Schumacher (Hrsg.), Wichmann; VDE Verlag GmbH: Berlin, Germany, 2018; pp. 284-295.

41. Spina, S.; Debattista, K.; Bugeja, K.; Chalmers, A. Point Cloud Segmentation for Cultural Heritage Sites. In VAST: International Symposium on Virtual Reality, Archaeology and Intelligent Cultural Heritage; The Eurographics Association: Genoa, Italy, 2011; pp. 41-48.

42. Familia Leica JetStream I Leica Geosystems. Available online: https://leica-geosystems.com/products/laser-scanners/software/ leica-jetstream (accessed on 25 September 2020).

43. Charef, R.; Emmitt, S.; Alaka, H.; Fouchal, F. Building Information Modelling adoption in the European Union: An overview. J. Build. Eng. 2019, 25, 100777. [CrossRef]

44. Graphisoft Archicad for TeamWork Announced. Available online: https://graphisoft.com/es/press-releases/atw (accessed on 3 November 2020).

45. Garyaeva, V. Application of BIM modeling for the organization of collective work on a construction project. MATEC Web Conf. 2018, 251, 05025. [CrossRef]

46. Hrynchak, P.; Batty, H. The educational theory basis of team-based learning. Med. Teach. 2012, 34, 796-801. [CrossRef] [PubMed]

47. Herrera, R.F.; Vielma, J.C.; Muñoz, F.C. BIM and teamwork of civil engineering students: A case study. Glob. J. Eng. Educ. 2018, 20, 230-235.

48. Borrmann, C.P.A. eWork and eBusiness in Architecture, Engineering and Construction: ECPPM; Taylor \& Francis Group: London, UK, 2015.

49. Qaravi, R. Agile Project Management within the BIM based Common Data Environment. Master's Thesis, University of Applied Sciences, Berlin, Germany, July 2018.

50. Atazadeh, B.; Kalantari, M.; Rajabifard, A.; Ho, S.; Champion, T. Extending a BIM-based data model to support 3D digital management of complex ownership spaces. Int. J. Geogr. Inf. Sci. 2017, 31, 499-522. [CrossRef]

51. Eseverrl, A.E. CDE o Common Data Environment, ¿qué es un CDE? I Espacio BIM. Available online: https://www.espaciobim. com/cde (accessed on 4 November 2020).

52. Oludare Idrees, M.; Pradhan, B. A decade of modern cave surveying with terrestrial laser scanning: A review of sensors, method and application development. Int. J. Speleol. 2016, 45, 71-88. [CrossRef]

53. Schnabel, R.; Wahl, R.; Klein, R. Efficient RANSAC for point-cloud shape detection. Comput. Graph. Forum 2007, $26,214-226$. [CrossRef]

54. Bassier, M.; Van Genechten, B.; Vergauwen, M. Classification of sensor independent point cloud data of building objects using random forests. J. Build. Eng. 2019, 21, 468-477. [CrossRef]

55. Ma, J.W.; Czerniawski, T.; Leite, F. Semantic segmentation of point clouds of building interiors with deep learning: Augmenting training datasets with synthetic BIM-based point clouds. Autom. Constr. 2020, 113, 103144. [CrossRef]

56. Dimitrov, A.; Golparvar-Fard, M. Segmentation of building point cloud models including detailed architectural/structural features and MEP systems. Autom. Constr. 2015, 51, 32-45. [CrossRef]

57. Nieto, E.; Moyano, J.J.; García, Á. Estudio constructivo del Palacio de los Niños de Don Gome (Andújar, Jaén), gestionado desde el proyecto HBIM. Virtual Archaeol. Rev. 2018, 10, 84. [CrossRef]

58. Instituto Nacional de Patrimonio Cultural. Instructivo para fichas de registro e inventario Patrimonio Cultural Inmaterial; INPC: Quito, Ecuador, 2011; ISBN 9789942070739. 
59. Brumana, R.; Della Torre, S.; Previtali, M.; Barazzetti, L.; Cantini, L.; Oreni, D.; Banfi, F. Generative HBIM modelling to embody complexity (LOD, LOG, LOA, LOI): Surveying, preservation, site intervention-the Basilica di Collemaggio (L'Aquila). Appl. Geomat. 2018, 10, 545-567. [CrossRef]

60. Quito, O.A. De Breve Historia de los Principales Terremotos en la República del Ecuador; Talleres G.: Quito, Ecuador, 1959.

61. Jouanen, J. Historia de la Compañía de Jesús en la Antigua Provincia de Quito 1570-1774; Fondo Ecua., Editorial Ecuatoriana: Quito, Ecuador, 1941. 